\title{
Health facility guidelines and management benchmarks: Improving workplace health services and health management in factories, farms and other workplaces in low- and middle-income countries
}

David Wofford

Marat Yu

Lauren Shields

Maria Pontes

Follow this and additional works at: https://knowledgecommons.popcouncil.org/departments_sbsr-rh

Part of the Demography, Population, and Ecology Commons, Family, Life Course, and Society Commons, International and Comparative Labor Relations Commons, and the International Public Health Commons

How does access to this work benefit you? Let us know!

\section{Recommended Citation}

Wofford, David, Marat Yu, Lauren Shields, and Maria Pontes. 2015. "Health facility guidelines and management benchmarks: Improving workplace health services and health management in factories, farms and other workplaces in low- and middle-income countries." Washington, DC: Population Council, The Evidence Project. 


\section{Health Facility Guidelines and}

\section{Management Benchmarks}

Improving Workplace Health Services and

Health Management in Factories, Farms and Other Workplaces in Low- and Middle-Income Countries

October 2015

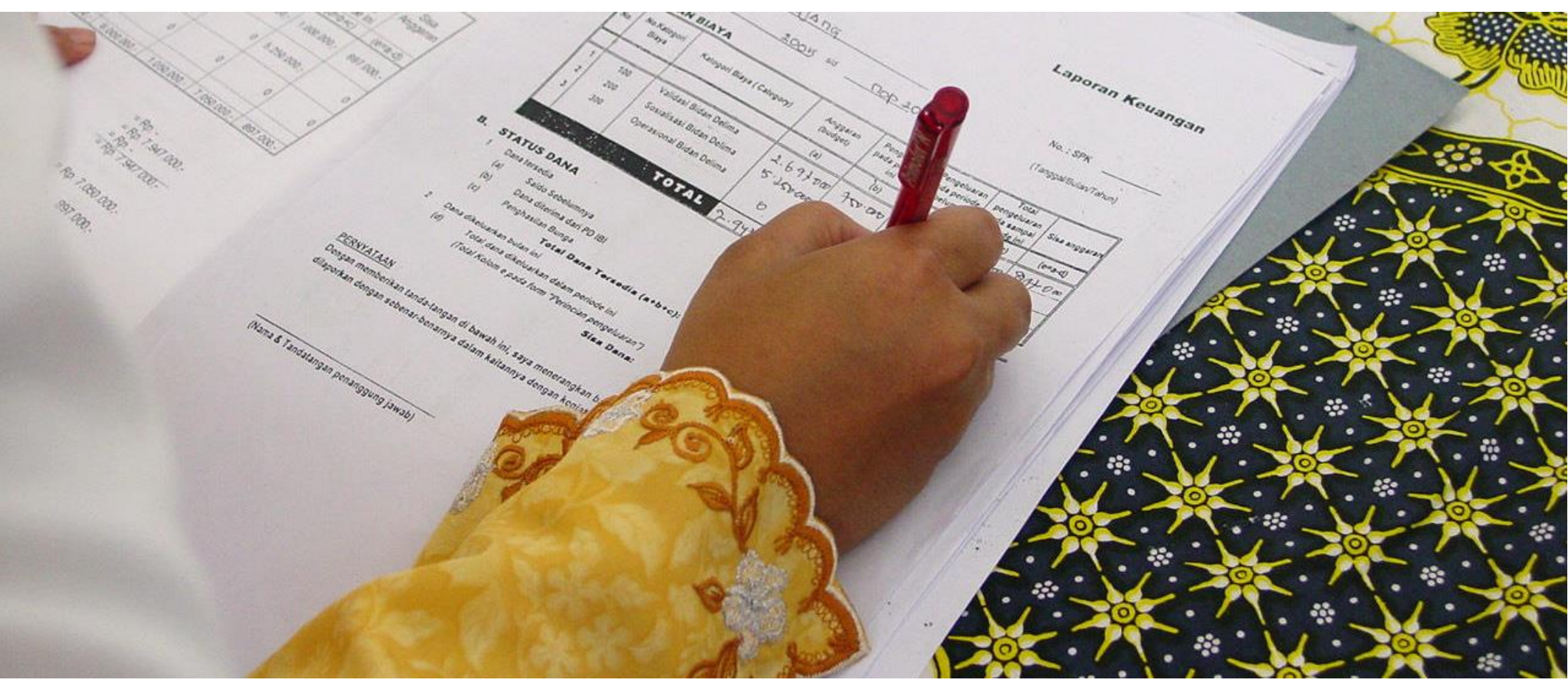


The Evidence Project

Population Council

4301 Connecticut Ave. NW, Suite 280

Washington, DC 20008 USA

tel +12022379400

evidneceproject.popcouncil.org

This document is a set of voluntary heath and management guidelines for corporations and their supply chains to promote continual improvement and application of good practices, better access to men and women's health services, and more effective use of health resources at workplaces in the developing world.

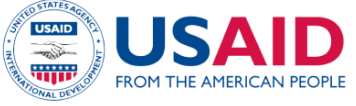

the Evidence Project and Pop

The Evidence Project is made possible by the generous support of the American people through the United States Agency for International Development (USAID) under the terms of cooperative agreement no. AID-OAA-A-13-00087. The contents of this document are the sole responsibility of Evidence

The Evidence Project uses implementation science-the strategic generation, translation, and use of evidence- to strengthen and scale up family planning and reproductive health programs to reduce unintended pregnancies worldwide. The Evidence Project is led by the Population Council in partnership with INDEPTH Network, International Planned Parenthood Federation, Management Sciences for Health, PATH, Population Reference Bureau, and a University Research Network.

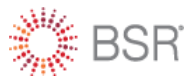

BSR is a global nonprofit organization that works with its network of more than 250 member companies to build a just and sustainable world. From its offices in Asia, Europe, and North America, BSR develops sustainable business strategies and solutions through consulting, research, and cross-sector collaboration. Visit www.bsr.org for more information about BSR's more than 20 years of leadership in sustainability.
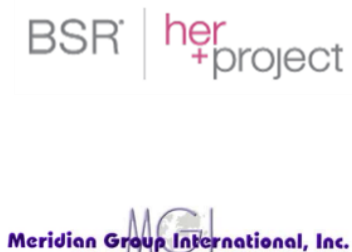

Meridian Group International, Inc. is a woman-owned, small business that works with the private and public sectors to create innovative programs and partnerships that benefit both business and society. RAISE Health is a major activity of the USAID-funded Evidence Project. Implemented by Meridian Group International, Inc., an Evidence Project partner, RAISE Health combines implementation science with its extensive experience implementing workplace health programs and promoting better policies and practices within the global framework of codes and compliance.

Published in October 2015.

Suggested citation: Wofford, David, Marat Yu, Lauren Shields, and Maria Pontes. 2015. "Health Facility Guidelines and Management Benchmarks," Washington, DC: Population Council, The Evidence Project.

(C) 2015 The Population Council, Inc. 


\section{Table of Contents}

Acknowledgments ........................................................................................................ iii

Section 1: Overview of the Workplace Health Facility Guidelines and Management

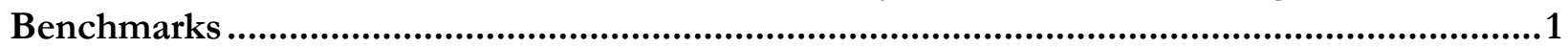

What is the Purpose of the Workplace Health Facility Guidelines? ................................................... 1

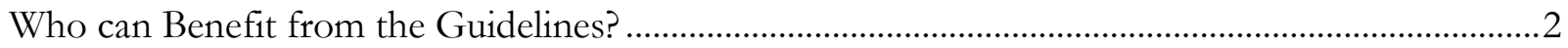

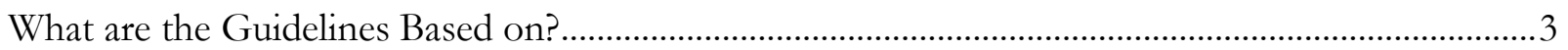

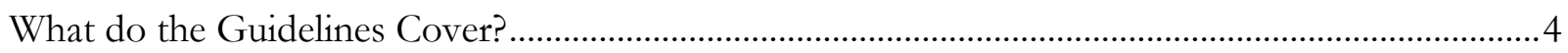

What Level of the Guidelines Should my Workplace Follow? ...............................................................5

Section 2: Workplace Health Services Guidelines .............................................................6

General Guidance on Using the Health Services Guidelines.............................................................6

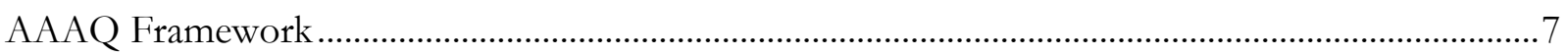

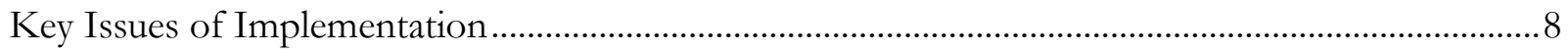

Health Services Guidelines and Indicators ……..............................................................................11

Section 3: Management Systems \& Corporate Leadership Guidelines ...............................17

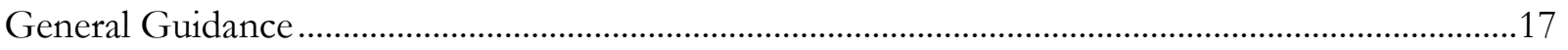

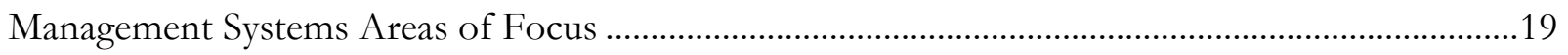

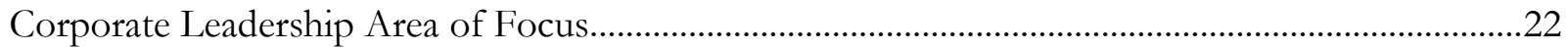

Management/Leadership Guidelines and Indicators ........................................................................23

Section 4: Appendices....................................................................................................26

Appendix A: Development of the Guidelines and Resources Used ..............................................26

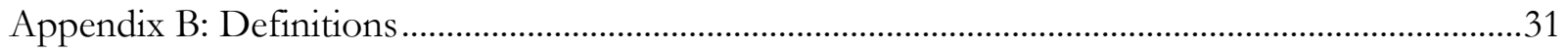

Appendix C: Healthy Workplace Model (World Health Organization) ...............................................33

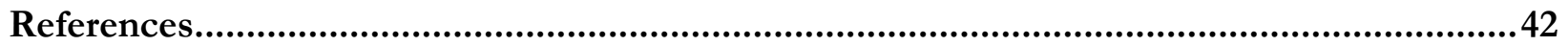




\section{Acknowledgments}

These guidelines were authored by David Wofford of the Evidence Project with Marat Yu, Lauren Shields, and Maria Pontes of Business for Social Responsibility's HERproject with support from Carolyn Rodehau of the Evidence Project and Luke Owsley, an independent consultant. The authors would like to acknowledge the following roundtable participants for their contributions to the development of the guidelines: Racheal Yeager Meiers (HERproject), Shawn Malarcher (USAID), Dr. Salwa Bitar (Evidence-to-Action Project), Dr. Shawn MacDonald (Verité), Meira Neggaz (Maria Stopes International), and Dr. Fabio Castaño (Management Sciences for Health). Further input was also received from the following field representatives of organizations that have workplace health programs: Dr. Bobby Joseph (St. John's Medical College), Asif Uddin Ahmed (CARE Bangladesh), Thou Chum (Marie Stopes International Cambodia), and Dr. Issa Wone (University of Dakar School of Medicine). Many thanks as well go to Ellen Weiss of the Evidence Project for her edits, ideas, and communications expertise and to Anneka Van Scoyoc of the Evidence Project for making the report, images, and appendices so visually effective. 


\section{Section 1: Overview of the Workplace Health Facility Guidelines and Management Benchmarks}

This guidance document provides the management of international brands or retailers and their supplier companies a set of voluntary guidelines for improving the health and well-being of workers in factories, farms, and other workplaces. It is focused on both the quality of health services provided at the workplace and the adequacy of company policies and management systems to ensure that workers have access to health services.

Every worker - every person - has a right to health; every company has a reason to invest in worker health beyond basic occupational health standards. The business case is strong for multinational corporations and their suppliers to invest in health services for their workers and ensure their access to primary health services.

\section{WHAT IS THE PURPOSE OF THE WORKPLACE HEALTH FACILITY GUIDELINES?}

The main goals of the guidelines are to:

1. Help enterprises - multinational companies and their supplier or subsidiary companies in developing countries - improve the management and the quality of workplace health facilities and services in cost-effective, practical, and auditable ways.

2. Ensure women and men workers in developing countries have access to primary health services, whether provided on- or off-site.

The guidelines address worker health using a gender lens. Women workers have specific health needs different from those of men workers that are often overlooked by managers. Furthermore, women workers generally have longer work days than men because of unpaid household and childcare obligations. Balancing these responsibilities can lead to greater stress, depression, and fatigue. Women's longer work day has direct consequences for their general and reproductive health as well as safety and productivity at the workplace. ${ }^{i}$

The guidelines provide management direction in assessing the quality of a company's health functions and set concrete targets. The purpose is to produce better health and business results from their existing workplace health and wellness investments, allocate resources more effectively, and address highpriority needs of women and men workers while creating shared value for the communities where companies operate. The guidelines address three areas:

1. Health Services - what practices and standards should be met by the health facility and its staff at the workplace.

2. Management Systems - how health services and staff should be managed by the enterprise.

3. Corporate Leadership and Policies - how leadership should support achievement of health standards and better, more integrated management of health operations.

Companies have much to gain from meeting these guidelines as part of ongoing quality improvement of health policies and practices for men and women workers. It has been documented globally that the unmet health needs of women and men workers lead to lower productivity, poor morale, higher turnover and absenteeism, and poor worker-management relations.ii

There is a strong business case for an expanded approach to occupational health by companies. While these standards do not envision workplace facilities to serve as primary care centers (although a few may, and 
many elements of primary care can be easily adopted), the guidelines make business sense in three important ways:

First, many workplaces already have in place health facilities and health providers that are often under-used and poorly managed. These health investments represent a cost already allocated (sunk cost), thus an underutilized business resource. No business would allow other productive resources to be as underutilized as many do with their health resources. Why should health investments be viewed differently?

Second, addressing the general health needs of workers benefits companies through both increased productivity and improved relationships with workers. Concern for health expressed through policies and practices signals overall corporate values and genuine concern for the well-being of workers that production bonuses, for instance, do not. Research in factories by the ILO/IFC Better Work Programme finds that managers significantly underestimate the value workers place on non-compensatory benefits like quality health services. iii It is not easy for workers to take care of their health. Many are poorly served by public and private health services or lack access to these services, due to their gender, migrant status, place of residence, unawareness, or restrictive workplace policies.

Third, better health services can strengthen buyer/brand-supplier relationships as there is a greater focus globally on worker well-being beyond minimal compliance.

Implementing the guidelines may involve new activities, but they should not be viewed as a new program. They should be seen as an extension of what enterprises already do or should be doing. Thus implementation is part of existing management functions and placed within the context of occupational health and safety, human resources, compliance, and other fundamental business operations.

\section{WHO CAN BENEFIT FROM THE GUIDELINES?}

The guidelines are applicable to most workplaces since many, by choice or by national law, have onsite health personnel and some type of health facility. However, the guidelines are not designed for those large companies that operate hospitals or fully functional primary care facilities that should be accredited by national or international standards organizations.

While these guidelines can be used by any enterprise in the world, they are designed to be used primarily by:

- Managers of factories, farms, and other workplaces in developing countries that supply products to multinational or national companies (MNCs), or managers of subsidiaries of MNCs.

- Health service providers at these workplaces.

Most managers do not know what to expect or ask of their health staff and facilities; most workplace health providers do not know what is expected of them. Without standards or guidance on health, companies are fated to have less healthy and productive workers and less return on their health investments. Company leadership and managers cannot manage their health practices if they have no frame of reference to manage against and to. Thus the guidelines are a vehicle for both better worker health and better business.

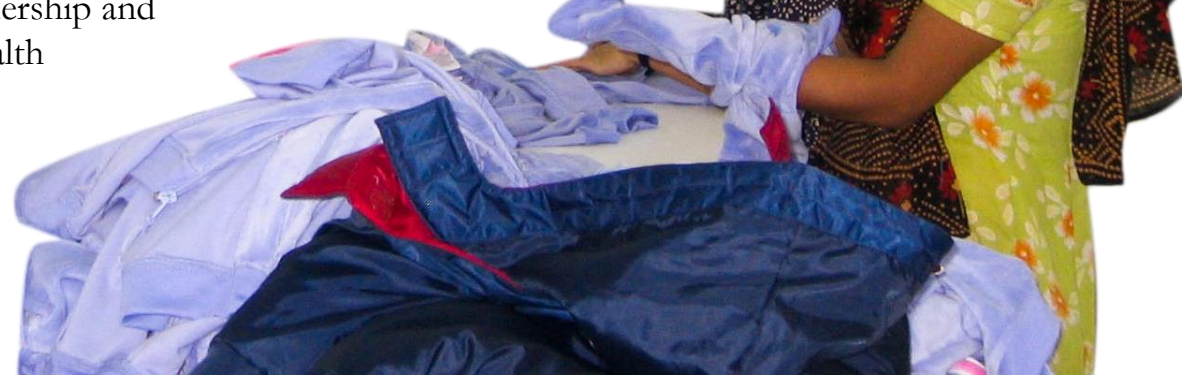


The guidelines also have relevance for:

- The leadership of MNCs in meeting global commitments, including obligations to respect and support human rights.

- The departments of MNCs directly involved in brand-supplier relationships, including purchasing, compliance, corporate social responsibility, human resources, and occupational health and safety (OSH) staff.

- Organizations that audit workplaces for compliance to corporate standards and policies.

- Government agencies that are responsible for the health of workers and communities.

\section{WHAT ARE THE GUIDELINES BASED ON?}

Workplaces vary widely in the types of health facilities, services, and providers they have on-site. These facilities (and the health services they provide) differ from primary health services in the public sector. Yet the guidelines aim to help companies ensure that workers have access to primary health services - as available in and relevant to the local circumstances - whether at the workplace or off-site or, in many cases, through a combination of the two.

The guidelines are based on internationally recognized primary health care standards, which have been selected for and adapted to the workplace by experts in public health, corporate sector partnerships, and workplace health services and facilities. (See Appendix A on the development process.) Factories, farms, and other private sector workplaces operate differently from the management structures of public health facilities, so workplace standards need to be adapted to be applicable to the reality of business in commercial workplaces.

The guidelines build on the United Nations Women's Empowerment Principles. They are also aligned with the Healthy Workplaces Model and Plan of Action of the World Health Organization, which promotes a comprehensive approach to worker health and safety that addresses risks as well as physical and mental health, health promotion, and social and environmental determinants of health.iv (Appendix $\mathrm{C}$ provides more information on the Healthy Workplaces model.) The guidelines differ not in intent but focus: They address specifically the health services, practices and policies in agricultural and industrial workplaces in the developing world and

\section{KEY DEFINITIONS}

Healthy Workplace

A healthy workplace is one in which workers and managers collaborate to use a continual improvement process to protect and promote the health, safety, and well-being of workers and the sustainability of the workplace..."1

\section{Health Facility}

Refers to any kind of physical location on-site that is dedicated to the provision of worker health services.

\section{Health Provider}

All personnel that are hired or contracted by a company to provide any level of health services at the workplace.

\section{Health Services}

Any of the activities that fall under definitions of the WHO and the Alma Atta declaration on primary health care: All services dealing with the diagnosis and treatment of disease, or the promotion, maintenance, and restoration of health.

See Appendix B for a discussion of definitions. provide specific indicators of good or best practices and protocols that should be adopted within those workplaces to ensure access to quality health services.

Most national laws have standards for occupational health and safety and require workplaces to keep records of workplace accidents and workplace related diseases. National standards and law always take precedence in the unlikelihood of a conflict with these guidelines. When there is no conflict (the majority of cases), companies should strive for the highest attainable standard. 
The guidelines are designed to complement occupational health and safety standards and fit into existing occupational health components within a company, including an enterprise's implementation of:

- National law and regulations governing workplaces and their health facilities.

- Workplace compliance protocols, requirements or practices for emergency and occupational health and safety.

- The United Nations Guiding Principles on Business and Human Rights and business's role to "respect" human rights and perform due diligence.

It is also important to emphasize that these Guidelines and related indicators represent a first step in developing workplace health guidelines or standards. We expect companies, organizations, and governments to adapt, revise, and expand the Guidelines and indicators as justified by the context and experience. For workplaces, the guidelines should be seen not as a compliance protocol but as a process of progressive realization of improved health management and services.

\section{WHAT DO THE GUIDELINES COVER?}

The guidelines are designed to be progressive, suggesting MINIMUM standards, while establishing a process for continuous improvement. Enterprises of any size should find it possible to attain the basic level for the guidelines within their budget and resource constraints.

The guidelines cover three broad categories ${ }^{v}$ and subcategories:

\section{Health Services (Section II) \\ - Physical Facility \\ - Products, Equipment, Materials \\ - Facility Policies \& Practices \\ - Provision of Care}

\section{Management Systems (Section III)}

3. Corporate Leadership and Policies (Section III)

Management Systems and Corporate Leadership are inextricably linked so they are discussed jointly in Section III.

Each category and subcategory has specific guidelines and indicators. This division follows common sense and experience:

- Companies need to make sure their health facilities, policies, and practices reach accepted quality standards (adapted to their situation and responsive to worker rights).

- Companies need to improve the way they manage health resources and staff - and integrate them into existing systems - to meet common health facility standards progressively.

Integrating health services into overall business systems requires leadership from the top, where management goals and policies are set and budget and personnel decisions are made.

Many of the actions required to reach the indicators under the guidelines cost very little to achieve. But they do require leadership from company senior management and support in terms of management systems to ensure changes in practices become part of basic operations. 


\section{WHAT LEVEL OF THE GUIDELINES SHOULD MY WORKPLACE FOLLOW?}

The guidelines comprise a set of indicators that are divided into three levels in recognition of the variety of health resources in different workplaces. This document is complemented by a Guidelines Assessment Scorecard that describes in detail each indicator, which workplaces should review and determine their capacity to meet them. These indicators are divided into three levels as a way to give general guidance to companies about what should be considered their baseline for beginning the process of continuous improvement on health management. The main difference between the levels is the number of indicators that must be met to achieve the standard.

All companies should reach this basic level regardless of size or resources. The levels provide a general description of company resources:

- Basic Level: Smaller workplaces with limited management and human resources staff and with minimal health facilities (e.g., a small health station in the production area), and low-level health staff (one or two health staff with limited medical training).

- Middle Level: Medium-sized workplaces with a larger management structure (compliance, human resources staff, data systems) with an infirmary or private health room (possibly one or more health stations), one or more certified/trained nurses, possibly with lesser trained health providers, and a part-time (or fulltime) doctor onsite.

- Higher Level: Larger workplaces with a more sophisticated management structure (human resources and compliance staff, OHS officer and trainers, data collection personnel) having one or more infirmaries and health stations, two or more qualified nurses, and at least one doctor on site 3-5 days a week.

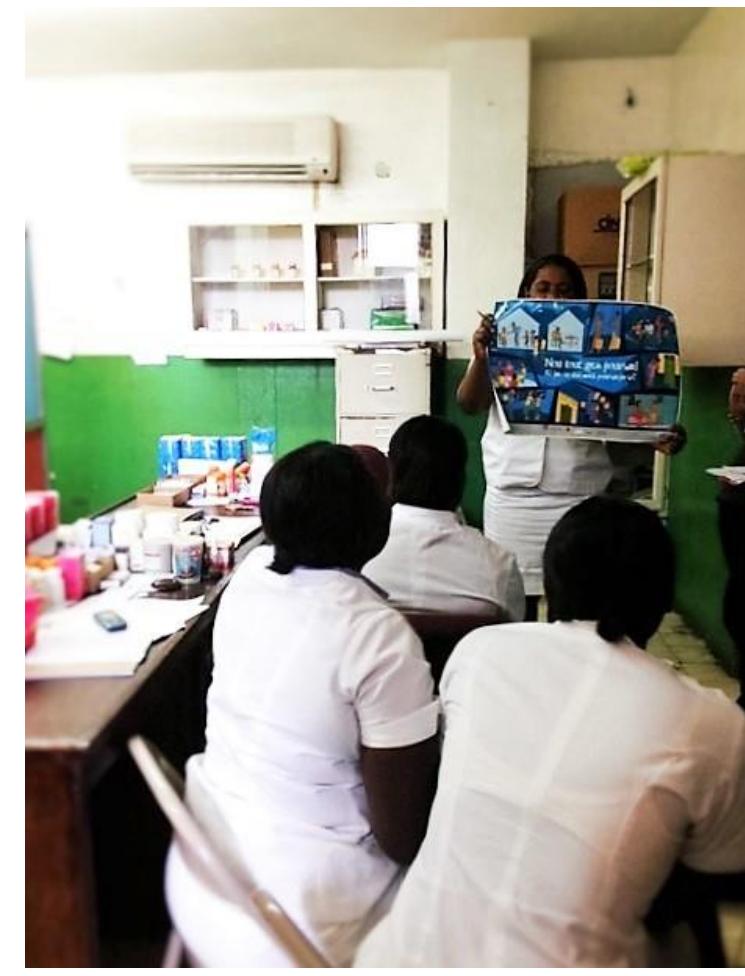

When using the guidelines, companies should focus less on the levels and more on determining the highest quality of services and health management systems they can achieve in their context. This may mean that a workplace may meet some indicators at the higher level but not all at the middle level. Size is only a rough approximation for resources and capacities. 


\section{Section 2: Workplace Health Services Guidelines}

Companies can do a better job of managing and using existing resources that will enable them to meet worker health needs and improve productivity. The place to start is with the health services, programs, practices, and personnel already in place. What are workplace health providers expected to do? Are they meeting minimal or good practices? Are they meeting the needs of both women and men workers? What is the quality of existing health facilities and what standards should they meet?

These health services guidelines help enterprises answer those questions and take deliberate action. To that end, this section has two parts:

1. General Guidance on Using the Health Services Guidelines:

- AAAQ Framework

- Key Issues for Implementation

2. Health Services Guidelines and Indicators by Category:

- Physical Facility

- Facility Products, Equipment, and Materials

- Facility Policies and Procedures

- Provision of Care

- Education/Counseling

The general guidance section explores broad issues related to workplace health practices. The accompanying Guidelines Assessment Scorecard provides details about what specifically is expected to meet each indicator and why the guidelines or indicators are necessary.

\section{GENERAL GUIDANCE ON USING THE HEALTH SERVICES GUIDELINES}

The assumptions behind the Health Services Guidelines are that:

- Most companies can and should do more to meet the health needs of women and men workers.

- Whatever level of health service a workplace provides, these must conform to accepted standards of quality and good practice.

- All companies must ensure workers have access to primary health services whether at the workplace, outside of the workplace or some combination of the two.

The guidelines do not assume that every workplace can or should establish a primary care facility on-site that meets all the health needs of women and men workers. But instead workplaces can and should adopt good practices expected of health providers and facilities.

Finally, in line with the WHO Healthy Workplaces model, the guidelines promote the idea that workplace health services need to go beyond the narrow framework of occupational health, which typically concerns safety-related health issues at the workplace. ${ }^{\text {ii }}$

A key goal is to promote preventive health care for workers - and prevention speaks directly to occupational safety and the business case for health. Sick or unhealthy workers can infect coworkers and lead to injuries that require treatment or emergency care. The poor health of workers costs money and harms productivity. 


\section{AAAQ FRAMEWORK}

Company management using the guidelines need to understand a basic framework for health rights.

Under international human rights, a person's right to health includes four essential elements: Availability, Accessibility, Acceptability and Quality. vii While this framework applies to the state's human rights responsibilities, it is also relevant to the workplace and business' respect for human rights. These terms are definedviii as followed:

- Availability: Functioning public health and health-care facilities, goods and services, as well as programs, have to be available in sufficient quantity.

- Accessibility: Health services must be accessible to everyone without discrimination, especially the most vulnerable people. They must be physically and economically accessible. Health services must be designed in a way that is responsive to local people's needs. Accessibility also includes the right to seek, receive, and impart information on health.

- Acceptability: All health facilities, goods, and services must be respectful of medical ethics and culturally appropriate, i.e. respectful of the culture of individuals, minorities, peoples and communities, sensitive to gender and life-cycle requirements, as well as being designed to respect confidentiality, and improve the health status of those concerned.

- Quality: Health facilities, goods, and services must be scientifically and medically appropriate and of good quality. This requires, among others, skilled medical personnel, scientifically approved and unexpired drugs and hospital equipment, safe and potable water, and adequate sanitation.

The AAAQ framework is reflected in all health care standards and has been adapted to the workplace context in these guidelines. These terms have important implications for workplaces - and management needs to understand them:

Availability and Accessibility. In terms of workplace health functions, it is important to understand the distinctions between these terms. Health services may be available in a community, but not be accessible to people for a variety of reasons, most typically limited hours of operation, cost, language, and location. The fact of employment in a factory or farm exacerbates the problem of accessibility. Workers often find that health services are not accessible after work hours, so their choice is to miss a day of pay to seek care. This leads to workers seeking care only when their symptoms are most acute and most costly to treat.

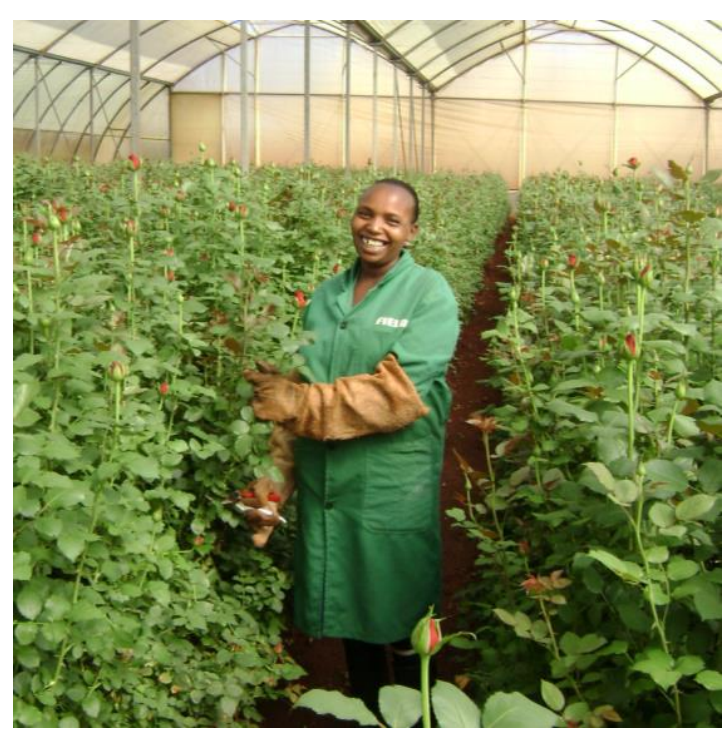

Accessibility is a major issue for women workers, who often have another work shift at home taking care of domestic responsibilities. Workplace polices that enable workers to seek services outside the workplace without penalty as well as increased onsite services can do much to help workers access the basic care they need. It is not uncommon for workplace health services to be available but not truly accessible because workers are under pressure not to use these services by line supervisors.

Acceptability and Quality. Company management often assumes that trained health providers onsite will operate according to accepted standards and therefore need limited management oversight. Experience shows the opposite that without stated company standards and health function practices, health providers do not meet many of the expected practices for acceptability and quality. For 
example, hazardous waste - needles, bloody bandages - are disposed of improperly and unsafely. Migrant workers, minorities, and women are too often treated with less respect than other workers. Health providers frequently have inadequate training, and there is little effort to enable some level of continuing medical education.

\section{KEY ISSUES OF IMPLEMENTATION}

It is common for companies to think that supervision of health functions requires medical knowledge and skills. In fact, the basic management of health operations - as opposed to the provision of services - requires the general skills of setting goals, adopting good policies and practices, and establishing systems of accountability.

The Health Services Guidelines provide companies the basic direction for managing their health activities against generally accepted standards - with the necessary input of health staff and experts. Managers and health providers using the guidelines need to address these issues:

1. Application/Scope. When applying the Health Services Guidelines, workplaces should determine which indicators are relevant to their context and what is the highest feasible quality of service they can achieve. An enterprise of any level is expected to meet all the guidelines (but not all the indicators) for this section.

2. Launch of Assessment/Improvement Process for Health Services. Each workplace will determine its own process for addressing the guidelines. It is always useful to seek the input of external experts or partners. However, the process should be driven by the company management itself - and the recommended approach for implementation (discussed further in Section 3) is developing a cross-department team that includes representatives from the health staff, human resources, compliance and OHS, and line supervisors and middle and senior management. The same is true of the Guidelines Assessment Scorecard: although it may be useful for external partners to provide technical expertise in reviewing the quality of health services, workplaces should take the lead in undertaking their own self-assessment of health function against the standard indicators.

3. Assignment of Responsibility for Health Services Guidelines. As part of long-term improvement and the implementation process, companies need to define clearly the lines of responsibility for health services and ensure that these fit into the existing management structure, so that the health staff, however large, fits into that overall structure. It is highly recommended that the health providers are assigned responsibility for meeting the Health Services Guidelines and held accountable. In larger companies, a reporting structure with defined roles within the health facility should be established, and the senior health provider at the workplace expected to be responsible for ensuring the all providers meet the guidelines.

Health providers, usually nurses, who are not given clear responsibility tend to adopt passive roles in which they wait for management to address any issues that arises rather than proactively anticipating needs and strongly advocating for action on areas required by the guidelines. For example, the standard for cleanliness: the provider is responsible for ensuring standard procedures for cleanliness are followed. This requires the availability of disinfectant, soap, and the like. Although management is responsible for budgeting for supplies and having a process for purchasing them whether by the providers or someone else, the health providers are nevertheless responsible for managing supplies, informing management of resupply needs, and most importantly ensuring that the facility is kept clean. The management role, in fact, should be to enable providers to assume responsibility for the guidelines. (Sections $2 \& 3$ discuss management systems, support, and leadership further.) 
4. Timetable. The goal is to put in place processes for continuous improvement and progressive realization of good and better practices within existing business systems. That said, the guidelines "team" needs to prioritize action on items that compromise safety and patient or provider health (hygiene, hazardous waste, confidentiality) and thus require immediate attention. And it should have a process for determining priorities and a plan for achieving the guidelines progressively over time.

5. Worker Health Needs. The guidelines intentionally do not define all the health needs of workers. The fact is the health needs of any workforce will change over time and will be different in each context. A key part of managing health is building the systems and skills to identify worker needs over time. Thus the guidelines promote collaboration and communication between management, workers, and health providers to identify and prioritize collectively the specific health needs of women and men workers.

Determining Needs. Workplaces have multiple ways to determine these needs, starting with good communication with workers through health and safety committees, worker representatives and unions, surveys, and any other existing workplace mechanisms. The health providers also have valuable insight into worker health needs, and the health facility data, if collected and analyzed appropriately, also provides valuable information. Finally, local public health officials can also give information about the needs in the community.

Addressing Needs. Each workplace will determine in its own way how best to meet workers' health and wellness needs - from services to products to education and counseling. It makes business and health sense to make full use of the skills and knowledge of the health staff already onsite and in many cases invest in increasing their capacities. There are many good models, and no single approach is best for all. One company may determine public and private services offsite are more cost effective, and put in place strong referral policies and support for workers. Another may find it is more effective to provide services on-site, either by using existing staff or hiring external service providers to visit the workplace several times a week. The key is ensuring worker accessibility to primary care services, whether onsite or offsite, that address their health needs. That is why the guidelines emphasize the importance of creating a referral system to external providers.

Providing Information, Education and Counseling. The guidelines name some basic preventive care and health promotion measures that are applicable in any setting, such as hygiene, nutrition, hydration, and reproductive health, and can be addressed in the factory setting. Health education and information is a service that can and should take place at the workplace. The guidelines list a few health and wellness areas that all workplace providers should be able to address, including basic health information at a minimum on hand washing, coughing, nutrition, ergonomics (stretching), and reproductive health/family planning (more below on reproductive health).

Counseling requires a higher level of knowledge and skills on the part of the provider who is trained in how to provide guidance and psychological support on specific health issues. Counseling requires additional training, but providers should be able to provide basic information, in a culturally sensitive way, on all the key health needs of workers and their communities. Companies with more capacity and resources should be more comprehensive in how they address relevant health and wellness issues and the ways they engage in worker health education.

6. Women Workers, Youth, and Disaggregated Data. The guidelines emphasize the importance of addressing health concerns of women workers, which are often not differentiated from those of men and thus ignored in workplaces. This emphasis is not to minimize men's health, but to ensure gender equity in health services. A key requirement that enables a clearer understanding of the specific health needs of workers is collecting and analyzing health data that is disaggregated by sex and age. By disaggregating data, management and health providers are better able to identify the specific health 
needs of women and men workers as well as the ones common to both. Disaggregation is also important to young workers, who are less able to assert their rights and face more challenges in accessing youth-friendly health services. It is not uncommon for health providers to treat young people rudely, dismiss their concerns, make inappropriate comments, or fail to answer their questions. This is especially true when it comes to sensitive health issues like reproductive health and family planning. Providers of health services can feel compelled to express disapproval of adolescents' behaviors, even though such expression is contrary to professional guidelines for health care settings. Young adults are particularly sensitive to rude or judgmental attitudes and behaviors. Their need for knowledge about reproductive and other health needs is high. They are more likely to engage in risky sexual behavior when in a new environment far from home without the support of their families and communities. Access to age-appropriate youth-friendly services in general can help prevent unintended pregnancy, HIV, and other sexually transmitted diseases.

7. Reproductive Health. Reproductive rights are human rights, and reproductive health services are a fundamental right of workers. Large numbers of workers are internal or external migrants living and working in a new situation, and their reproductive health needs are affected by the condition of their employment. Companies should consider how their policies and practices enable or inhibit access to reproductive health services. "Do no harm" is a key concept in occupational health - and workplaces in compliance with OHS standards focus on chemicals that can harm fertility or pregnant women. Yet workplaces can also do harm by not ensuring that women - and men workers have access to needed reproductive health services. Furthermore, workplaces can do much good in promoting reproductive health for these workers. Workplace health providers can play an active role in ensuring a worker receives quality reproductive health services, including access to the contraception he or she needs, and education on various options and correct use based on the principles of free and informed consent.

8. Pharmaceutical and Health Products. The guidelines do not define the medicines that should be onsite beyond basic pain relievers. The World Health Organization provides a list of essential medicines, which gives guidance about drugs and usage related to specific services. For the most part, most of these drugs will not be available at workplaces with limited onsite services. Providing medications can be a very useful service to workers, but this requires that the health providers are properly trained and medications are stored in a locked area with a supply management system to track usage. Antibiotics, in particular, are misused and are leading to dangerous resistance to these life-saving drugs.ix Thus workplaces that provide antibiotics can and should play an active role in educating their workers on correct use, and health providers must provide good patient oversight to make sure the antibiotics are taken as directed. Otherwise, it is prudent to have a strong referral system to qualified 
health providers. Access to family planning products has also been done effectively through onsite or mobile services at workplace or referrals. The one product that all workplaces should make available to women workers is sanitary napkins.

9. Repetition within the Health Service Guidelines. There may appear to be some repetition among indicators of different guidelines in this section, but this reflects different elements of the same goal. For instance, under the Physical Facility guidelines for confidentiality, one indicator requires a locked space for patient records. Under the Facility Practices/Procedures guidelines for confidentiality, an indicator requires the health providers to keep patient records in a secure, locked location. These two indicators are not the same: one refers to having the capacity to secure records (a locked drawer or room); the other, to the standard practice by the provider of keeping records in a locked space.

10. Definition of Patient/Client. The guidelines define "patient" in the workplace context as anyone being served by the health facility, which in most cases will only be company employees. Company employees comprise everyone from production workers to supervisors, and middle and senior management. In some cases, the workplace health facility also provides some services to patients who are dependents. Many health organizations prefer the term "client" to patient, but both terms are used here with respect to workplace health facilities. (See Appendix A for further definitions.) However, where the guidelines call for health providers to be proactive in health education, the term worker may be used because these activities often do not take place in the health facility or in the context of a provider-patient interaction.

\section{HEALTH SERVICES GUIDELINES AND INDICATORS}

Here is a quick overview of the guidelines and indicators. The companion Guidelines Assessment Scorecard provides the rationale for the guidelines and indicators, the level (basic, middle, and higher) assigned to each indicator, and guidance on achieving them.

\section{PHYSICAL FACILITY GUIDELINES}

1.1 CLEANLINESS - Health facility is kept clean.

Indicators:

1.1.1. Soap and running water OR hand sanitizers are available for hand washing at the health facility.

1.1.2. Dedicated cleaning materials and disinfectants are available for cleaning furniture and instruments.

1.1.3. Waste receptacles are on site.

1.1.4. Workspace is not dirty or messy.

1.1.5. Hot water is available and easily accessible in facility

1.2 CLIENT/PROVIDER SAFETY - The facility does not expose clients or providers to health hazards.

\section{Indicators:}

1.2.1 A dedicated disposal receptacle for hazardous materials, separate from general waste, is in the facility.

1.2.2 A separate container for disposing of needles is available.

1.2.3 No expired medicines are onsite.

1.2.4 Hazardous waste is disposed of by a hazardous waste service (private or public) provider.

1.3 PRIVACY \& CONFIDENTIALITY - The facility ensures client privacy and protects confidential information.

Indicators: 
1.3.1. Space is provided where the provider and client can speak privately and not be overheard.

1.3.2. Waiting area is separate from examination or intake area.

1.3.3. Facility has a secure location in which client records can be locked.

1.3.4. Facility is not a passage, exit, or entrance for non-clients.

1.3.5. A private space separate from client intake is provided for client exams, counseling, and other communications.

\subsection{LIGHTING \& ELECTRICITY - Electricity and adequate lighting is provided.}

Indicators:

1.4.1. Adequate lighting is available to perform functions.

1.4.2. Electricity is available in the facility, supported by a generator, to perform functions.

1.5 FURNITURE - Adequate furniture is provided for client services.

\section{Indicators:}

1.5.1. A desk/table and chairs are available for consultation.

1.5.2. A locked cabinet to store medicines and other supplies is on site.

1.5.3. A bed is available for rest and care.

1.5.4. An examination table is available for clinical services.

1.6 RECORD-KEEPING - Health records are maintained for each patient/client.

Indicators:

1.6.1. A registry book is used for documenting client intake and consultations.

1.6.2. All information gathered identifies the sex of the client, employee number, and mobile phone number (if available).

1.6.3. Forms tracking individual client history, services, and follow up are used.

1.7 PUBLIC INFORMATION - Information on health services is publicly posted in the facility and in the workplace.

\section{Indicators:}

1.7.1. Facility and health provider hours and services are posted in front of the clinic.

1.7.2. Facility and health provider hours and services are posted in one or more public spots.

1.7.3. Provider responsibilities to patients/clients are posted in the facility: informed decisionmaking, right to refuse care, client-centered care, and confidentiality.

1.7.4. Workplace policies on workers' access to health services during and after work hours are posted in and near health facility/spaces.

\section{FACILITY PRODUCTS, EQUIPMENT, AND MATERIALS GUIDELINES}

2.1 INSTRUMENTS - The facility is stocked with instruments and materials appropriate to the level of services provided.

Indicators:

2.1.1 A first aid kit is kept stocked with bandages and other items required by law and basic needs.

2.1.2 Washing products are available for cleaning wounds.

2.1.3 Provider has access to thermometer, weight, scale, and tape measure.

2.1.4 Stethoscope and a blood pressure cuff or machine are available.

2.1.5 Protective gloves (preferably non-latex) are available.

2.1.6 Equipment/products for specific tests or services offered by the facility are available. 
2.2 MEDICINES - Basic medicines are available appropriate to the services provided. Indicators:

2.2.1 Non-prescription pain reliever is available.

2.2.2 Medicines and immunizations are available based on illnesses specific to the workplace/community and training of health provider.

2.3 REPRODUCTIVE HEALTH - Reproductive health products are made available to workers.

\section{Indicators:}

2.3.1 Sanitary napkins and/or other products for menstruation are available to workers.

2.3.2 Treatment for urinary tract and gynecological infections are made available onsite or offsite by a qualified provider.

2.3.3 Modern contraception is made available in the facility or through other mechanisms onsite or via formal relationships with providers offsite.

\subsection{HEALTH EDUCATION PRODUCTS - Health educational materials appropriate for the} literacy level and in the language of workers are available.

\section{Indicators:}

2.4.1 Health education materials are posted on walls in the clinic, bathrooms, and production areas (as appropriate).

2.4.2 Health education materials are available as handouts for workers at a reading level that reflects their literacy.

2.4.3 The facility provides information (posters and/or handouts) on topics that are related to disease prevention or health protection of the workforce: correct use of antibiotics, hand washing, hydration, nutrition, family planning ergonomics/stretching, and coughing.

2.4.4 The facility provides information (posters and/or handouts) on topics that are specifically relevant to women workers: menstrual hygiene, spacing pregnancies, pre- and post-natal care, and urinary/gynecological infections.

2.4.5 Materials are available that address essential health problems or issues in the workers' local community, such as sexually transmitted diseases, reproductive health/family planning, harassment/gender-based violence, mental health, and common health conditions in the locale (cancer, HIV, tuberculosis, malaria, alcohol/drugs, anemia, etc.).

\section{FACILITY POLICIES/PROCEDURES}

3.1 HYGIENE PROTOCOLS - Health providers follow good hygiene practices.

\section{Indicators:}

3.1.1 Hands are cleaned between client visits.

3.1.2 The work space is cleaned and disinfected as necessary each day.

3.1.3 Protective gloves are worn whenever there is contact with blood or bodily fluids.

3.1.4 Hazardous materials (blood, bandages, needles) are always put in a safe disposal site, separate from other trash and not put part of the routine handling of trash.

3.1.5 Instruments and examination furniture are disinfected between client visits.

3.2 CONFIDENTIALITY - Health providers take precautions to protect confidential information.

Indicators:

3.2.1 The provider provides the client's medicines, products, counseling, or information in a way that ensures his/her confidentiality. 
3.2.2 The provider keeps all client information in a locked site when providers are not in the facility.

3.2.3 The provider never shares individual client information with management, workers, nonhealth professionals or any other person without a medical need to know.

3.3 CLIENT/PATIENT PROTECTIONS - Providers follow common practices for outside observers during patient services.

Indicators:

3.3.1 Clients are informed that they may have a second person of their choice with them at any time when receiving care from or consulting with a provider.

3.3.2 A second person of the same sex as the client is present when the provider is of a different sex and undertaking a physical exam beyond vital signs.

\subsection{AVAILABILITY OF SERVICES - Health services are made available to workers.}

\section{Indicators:}

3.4.1 The facility/workplace has the minimal number of health staff and level of qualifications required by law.

3.4.2 The health staff takes lunch at a time different from the workforce.

3.4.3 Workers may leave during work hours at no penalty to receive non-emergency services they need, if these are not accessible to the worker at a reasonable cost during non-work hours.

3.4.4 A health facility with more than one provider is never closed during the day.

3.4.5 Workers have access to the health facility for non-emergency matters during work hours.

3.4.6 Workplace health services or programs are extended to workers' spouses and children.

\subsection{CLIENT SCREENING - Client screenings are routinely performed} Indicators:

3.5.1 Clients are asked basic screening questions to inquire about general health status beyond the specific health issue being treated.

3.5.2 The height, weight, blood pressure, and temperature of clients are taken as a routine part of services.

\subsection{INVENTORY MANAGEMENT - Inventory of supplies and medicine is managed to} ensure quality and sufficient supplies.

\section{Indicators:}

3.6.1 Providers check supplies each week (first aid kit, medicines, etc.) to cover worker needs.

3.6.2 The providers track supplies available in the facility to prevent stockouts or unauthorized use of medicine.

3.6.3 Medicines are procured from reputable companies or organizations that are recognized as ensuring high-quality products.

3.7 GRIEVANCES/COMMENTS - Existing grievance systems or worker-management processes address health issues and provision of healthcare in the workplace.

\section{Indicators:}

3.7.1 The facility has a sign indicating workers can raise any concerns about health services or treatment through the existing grievance processes and suggestion boxes.

3.7.2 Comments/complaints are reviewed by management and shared with providers.

3.8 CLIENT RECORDS - Client records are maintained and used for ongoing patient care. Indicators: 
3.8.1 Workplace is in compliance with any legal requirements to record and report on workplace accidents and related diseases.

3.8.2 Health providers record on paper or registers basic health information of the client, including sex and services rendered.

3.8.3 Providers store all client health records in a cabinet or private space that is locked at the end of each day.

3.8.4 File folders with individual client records are kept if providers perform health screenings and vital signs and provide medical treatments or services onsite.

3.8.5 Health records and data are regularly reviewed by providers to ensure follow-up with individual clients.

3.8.6 Health records and data are regularly analyzed to identify worker health trends and needs overall and by age and sex.

3.8.7 Health needs and trends of workforce are reported to management.

\section{PROVISION OF CARE}

4.1 REFERRALS - Effective referral services are provided to workers.

\section{Indicators:}

4.1.1 Provider makes available to clients accurate referral information on available public/private health providers, including exact location, hours of operation, sex of providers, types of services, costs (if not free), availability of health products, and general quality of care.

4.1.2 Provider follows up with client to ensure the referral took place and services were received.

4.1.3 Health provider refers clients needing family planning to facilities and/or pharmacies where family planning methods and emergency contraception are available.

4.1.4 Provider has a referral contract with public and/or private service providers.

4.2 PROVISION OF CARE - Health providers use a "client-centered approach" with workers.

\section{Indicators:}

4.2.1 Health providers demonstrate (a) concern for the client's overall health needs; (b) lack of negative judgments expressed orally or physically about client health issues or client's sex; (c) friendly provision of services; (d) respectful responses to client choices and questions; and (e) protection of confidentiality.

4.2.2 Clients are informed that they may refuse treatment at any time.

\subsection{ADDITIONAL SERVICES - Workplace addresses unmet health needs of women and men workers onsite.}

\section{Indicators:}

4.3.1 Health provider has taken at least one continuing medical education or health training course each year to improve existing services or expand services offered.

4.3.2 Health providers are in compliance with their professional requirements for licensing and continuing medical education.

4.3.3 Health team reviews information gathered at least once a year (from facility data, meetings with workers and worker representatives, supervisors, health providers, surveys/focus groups and/or external public health information) to identify any critical unmet health needs of women and men workers.

4.3.4 Workplace takes action to address the unmet health need(s) of workers prioritized for that year.

4.3.5 Screenings for prevalent non-communicable diseases are offered onsite or offsite once a year. 


\section{EDUCATION/COUNSELING}

5.1 HEALTH EDUCATION/PATIENT COUNSELING - Health providers perform health education or counseling services at the workplace.

\section{Indicators:}

5.1.1 Provider plays a proactive role in improving worker health through formal and informal education outreach in the clinic facility or at worksites, where possible, with groups of workers or individual workers.

5.1.2 Provider provides basic health information to workers on nutrition, general and menstrual hygiene, stretching, coughing, and reproductive health/family planning as well as occupational health risks.

5.1.3 Provider provides basic health information on leading health issues in the community, such as waterborne and infectious diseases, maternal and child health and any other health issues that are known risks to workers (diabetes, TB, HIV/AIDS, malaria, heart disease etc.)

5.1.4 Provider provides counseling on family planning methods and reproductive health based on principles of free and informed consent.

5.1.5 Provider provides counseling on critical public health issues affecting workers. 


\section{Section 3: Management Systems \& Corporate Leadership Guidelines}

Management systems are an essential component for achieving the guidelines since sustainable and continuous improvement of services requires the oversight and engagement of enterprise managers, not just health facility staff. That's why corporate management and leadership are included in the guidelines.

Management sets the expectations and provides the resources and support to meet those expectations. And health providers need to know the standards and practices they are expected to meet. Good health practices do not happen by magic or dint of professional degrees.

The effective functioning of workplace health services requires they be integrated into overall business operations. Health is not integrated very well into business due to at least two false assumptions:

1. Good clinical practices are being followed just by virtue of hiring (trained) health providers.

2. A lack of expertise in medicine or health means managers cannot play an effective role in supervising health operations.

The Management Systems Guidelines help managers think through various functions and systems that may be used for oversight of health services as well as offer guidance for actions. The Corporate Leadership Guidelines focus on the policies and direction enterprise leaders need to set to address health more effectively at the workplace.

This section has two parts:

\section{General Guidance on the Guidelines}

- Management Systems Areas of Focus

- Corporate Leadership Areas of Focus

\section{Guidelines/Indicators for Management Systems and Corporate Leadership}

\section{GENERAL GUIDANCE}

These guidelines are designed to fit into existing management systems. This starts with existing occupation health and safety systems, which should be integrated, but often are not, into the overall business functions, from human resources, to finance, to planning and investments. These functions comprise such activities as:

1. Budgeting

2. Strategic planning

3. Performance evaluation and annual review

4. Workforce development and training

5. Hiring and recruitment

6. Compliance with laws, codes, and contracts

7. Procurement

8. Worker engagement (collective bargaining, grievance mechanisms)

9. Benefits and compensation 
Workplace health operations and staff are largely bystanders in these processes, more often seen as a cost center than a component of production and productivity. Ironically, evidence points to a pronounced lack of focus by managers on the productivity and effectiveness of their health personnel whereas most have an ongoing, if not intense, focus on productivity of their other workers. This fact becomes starker in light of growing evidence that effective health promotion and prevention enable greater productivity and well-being of workers.

The task at hand, therefore, is not to create new systems but to bring workplace health operations into the processes management already uses. Small enterprises with limited resources will have fewer management systems but nonetheless can integrate its workplace health service into the functions they do have.

Corporate leadership, of course, is essential. The top leaders create the corporate culture, define priorities, set the strategic direction, and determine rewards and recognition for performance. Senior and middle managers takes their cues from the top. The CEO signals the importance of health through not only words but also policies and action.

Most line supervisors know the only metric of success is meeting production and quality quotas.
BSR'S GAP ASSESSMENT OF READY-MADE FACTORIES IN BANGLADESH

The ready-made garment (RMG) industry is Bangladesh's greatest contributor to GDP growth and has played a significant role in the country's improved performance against world development indicators. However, the RMG industry has grown rapidly in Bangladesh within a context of limited social or physical infrastructure to support it.

With the support of UKaid, BSR conducted a gap assessment of onsite healthcare services and facilities in 10 RMG factories in Bangladesh from June to July 2014, examining human capacity, operational management, and company policy. The study found five main gaps in the healthcare systems available at these factories: (1) Nurses lack necessary skills and qualifications to perform their job optimally; (2) Insufficient attention is given to health education and promotion of women's health issues; (3) Clinic facilities require upgrading to better serve health needs; (4) Factories' healthcare management systems require strengthening; and (5) Health staff are insufficiently prepared to respond to emergencies.

Improving workplace clinics and factory nurses' capacity has enormous potential to bridge some of these gaps and efficiently link RMG sector workers, especially women, to the health products and services that they need.

That is what they are rewarded for. These metrics give no value to worker health. For most supervisors, the worker who receives health services is taking immediate time away from work. They do not consider the longer term benefits of reduced absenteeism and higher productivity. Only top leadership can communicate the value of health to overall business success; but this means the CEO must do more than communicate. The CEO must ensure that health is integrated into policies, processes, and systems.

The guidelines provide a framework for corporate leadership to take action on worker health and well-being. Although the guidelines are very specific about implementing universal good practice relating to clinical care and facility operations, they do not direct enterprises on how to ensure availability and accessibility to health services. Top leadership needs to drive both continuous improvement of services and innovations in health services. There are many different models for expanding access to health for workers - whether at the workplace, in the community or a combination of both. Each enterprise should view worker health as a need to be addressed in a cost-effective way, not one to be avoided. 


\section{MANAGEMENT SYSTEMS AREAS OF FOCUS}

What does fully integrating health services into management systems look like? While every workplace will have different capacities, the Management Systems Guidelines give concrete details for ways that an enterprise should manage health as part of its operations. These comprise:

1. A designated workplace manager responsible for supervision of health functions and practices. A senior person in management, who can make decisions or facilitate decision-making, should have responsibility for oversight of health services and be accountable for performance of health staff. This person may be in human resources, compliance, the front office, or another function. He or she does not need to have health expertise. The manager's role is three-fold:

- Accountability for following the guidelines and other policy goals.

- Support to the health staff (called supportive supervision).

- Application of management processes.

Some larger enterprises may already have a health clinic manager overseeing operations who can assume some or much of this role. Nevertheless, the enterprise should designate a manager external to the clinic to ensure accountability and integration with other management functions described below. Accountability and supportive supervision go together as health staff cannot be held accountable if they are not given the tools or training (as needed) to meet new expectations.

2. Human resources processes and tools. While smaller workplaces may not have a human resources department, all perform some of these human resource functions:

- Job descriptions/responsibilities based on the guidelines. Management needs to set clear expectations of workplace health providers by developing job descriptions that are reviewed annually. Ideally, these are written and used as part of annual reviews, hiring, and compensation or bonuses. The purpose is to define areas of responsibility and expected practices informed by the guidelines. In the likelihood that job descriptions do not exist, the workplace health providers should be part of the process of defining responsibilities and developing descriptions using the guidelines for guidance. In developing job responsibilities, it is important to define spheres of control where the providers have decision-making authority so that important activities or functions do not take place as staff waits for approval.

- Organization chart/organogram. In workplaces with multiple health providers, it may make sense to create an organogram showing reporting structures and accountability. The organization chart enables all staff to understand their roles as they relate to each other. For instance, if everyone shares the responsibility for managing supplies, which is common, this leads to stock-outs as no one is clearly responsible.

- Annual review. Health providers should have an annual review with the dedicated manager (and others as appropriate) when goals for the year are evaluated and new ones set, job responsibilities reviewed, and any concerns or needs discussed. The job description can be changed as necessary as part of this process.

- Hiring and firing. With job descriptions and clear responsibilities, health providers should be hired or terminated through a standards-based process. Too often, enterprises use informal networks to find health providers without any discussion of expectations, responsibilities, or job descriptions. A more formal process will enable workplaces to identify more qualified candidates but, as important, set the expectations for proactive health services and education. 
The guidelines with job descriptions and responsibilities also enable the workplace to identify health providers who are not meeting the new practices under the guidelines and start a process of capacity building or, if necessary, termination. In most cases, health providers are eager to adopt more proactive practices, but many do need supportive supervision in building these skills.

- Workforce development and training. All health providers need ongoing capacity building and training to maintain and expand their skills. At the highest levels, this is called continuing medical education and is part of certification. For most workplaces, the providers need to build skills. These may include training in a specific health area (preferably a condition affecting workers), counseling skills, participatory education techniques, client-centered services, or certain clinical skills. Within the available resources, management can send the providers to external trainings as well as hires external experts to provide training or skills building on site. The determination of providers' training needs should be done individually and collectively (where there are multiple providers). As part of the development process, the knowledge acquired and new skills learned from external trainings should be shared with the health staff.

- Compensation. Health provider compensation should be aligned with compensation policies for other employees (as allowed under national laws). For instance, if the enterprise provides bonuses to some or all of their workers based on performance and production goals, management should consider similar kinds of performance for the health staff in achieving indicator under the guidelines.

3. Data collection and analysis. Workplaces, particularly industrial ones, collect productivity data error rates, production quotas, absenteeism, turnover, etc. - and analyze the data to cut costs and improve performance. Workplace health facilities collect data - sometimes well, sometimes poorly but rarely do health providers or workplace managers analyze the data to plan activities or assess performance. It is even rarer for managers to analyze production and health data together to assess the impact of health on productivity. Much of the health data collected relates to occupational health issues - injuries, exposures - and fails to include primary health issues. Research shows that poor health is a frequent reason for worker absenteeism; it also affects performance on the job.

- At the health facility level, providers can use the data from patient visits and worker outreach to identify leading health issues and trends over time. They should use this data to determine the kinds of health promotion and educational activities to develop, evaluate the effectiveness of these activities, and identify areas for skills development.

- At the management level, the data (coupled with operations and other data) can be used to determine the business return from health services (lower absenteeism, turnover, errors, etc.), additional health services (on site or off) worth further investment, and the effectiveness of current health activities. It should be emphasized that the health data used by management must be in an anonymous form that does not divulge any confidential information about individual workers.

4. Planning, deliberative, and review processes. These processes range from staff meetings to strategic planning sessions, and are typically structured to take place at defined times during the year. These processes need to be established or improved at the facility level, and health service issues need to be addressed within these processes at the management level.

- Health facility level. If the enterprise has two or more health providers, they should have structured meetings to discuss challenges, plan activities, set goals, assess progress, and identify worker health needs through data analysis. In a workplace facility with only one provider, these 
activities will take place with the management supervisor. Each workplace will determine how best to structure these meetings, but this is a common approach:

- Weekly staff meetings of facility health providers themselves where the group discusses issues and educational activities for that week.

- Monthly meetings with providers, management supervisor, and other relevant staff, which may include the safety officer, compliance officer, union representative, and other relevant employees.

- Annual planning and review meeting with the broader group for longer-term setting of goals (worker health needs, improvement of clinical practices, educational and health promotion targets, equipment and product needs, etc.) and creating an action plan.

- Management level. Workplace health issues should be on the agenda in similar processes that take place with middle and senior management relating to company operation. The health facility supervisor plays a key role in engaging management on these issues but also ensuring the appropriate health provider is brought into or is more fully engaged in other management-led processes, including:

- Health and Safety Committee. Health providers, typically nurses, should be active members of these committees, which should pay attention to adequate demographic and functional representation. Furthermore, management should ensure that the health provider plays more than a perfunctory role on the committee and actively engage the group to consider worker health issues beyond occupational safety.

- Worker grievance and consultation mechanisms. Health services should be included in any grievance mechanisms. Worker comments should be shared with the providers, who should be part of the response or redress process. Worker comments should be part of the health providers' annual review. Also, when management consults workers on health issues, the health providers should be part of the process. From a broader perspective, effective health providers who have earned the trust and confidence of workers are in a unique position to gain insights into worker health and non-health concerns that line supervisors and senior management may not have. While providers must not undermine that trust or divulge personal information, management should include them in efforts to understand worker needs.

- Compliance audits. Management should include the health staff as individuals to be interviewed by workplace auditors as part of monitoring the operations.

- New worker orientation. Orientations should include a place on the agenda for nurses/health providers to talk with workers about health policies, promotion, and services; and should include a visit to the health facility. Occupational health and safety concerns should also be addressed part of the orientation.

- Training programs. In workplaces that have onsite training programs for new or existing workers, the training site may be an effective place for health providers to provide health education within the larger training curriculum.

5. Budgeting. The budget determines priorities for the enterprise and is at the heart of management systems. The health operations should be part of the budget process as this is essential if a continuous improvement process under the guidelines is to be achieved. The goal is for the enterprise to do much deeper analysis of the costs and benefits of health investments at the workplace. Research by the ILO/IFC Better Work Programs suggest that firms not only undervalue non-compensatory benefits, such as health services, that workers value highly but also may fail to see the benefits of these because they under-invest in them. ${ }^{x}$ 
All these are components of basic management applied to the health facility. They do not require special expertise; they do not require typically new systems. They require that management treat health services like other parts of the operation. The implementation process in Section III provides guidance on addressing these items.

\section{CORPORATE LEADERSHIP AREA OF FOCUS}

Corporate leadership is necessary for worker health and well-being to be integrated into management systems. From a corporate culture perspective, the enterprise's stance toward worker health and well-being is about more than just improved productivity. Genuine concern for worker health, demonstrated through good policies and practices, is an important way that an enterprise communicates that it values workers and expresses its overall corporate values.

The Corporate Leadership Guidelines provide two areas of focus for CEOs:

\section{Health and Corporate Goals and Values}

\section{Corporate Policies and Accountability}

The first point is that almost all of the indicators associated with these areas require no additional outlay of money. There are no doubt costs associated with addressing these issues, mainly staff time and capacity building. But the guidelines are essentially about applying basic management processes and leadership activities to health. Whatever costs that entails comes with the benefit of a better managed and better led organization because an area that affects worker productivity is now being treated as an essential business concern.

In addition, gender is possibly the most unrecognized area for rigorous leadership attention when it comes to worker health (and other issues). The default worker in the minds of many managers is a man. Women's concerns are not well understood and attention to them is often perfunctory: common standards for occupational health and safety are justly concerned with protecting pregnant women from hazardous exposures and undue strain. Yet, more broadly, a range of factors affect women workers' health and wellbeing that are different from those that affect men. Top leadership needs to communicate throughout the operation that it recognizes the different health - and common health—needs of men and women.

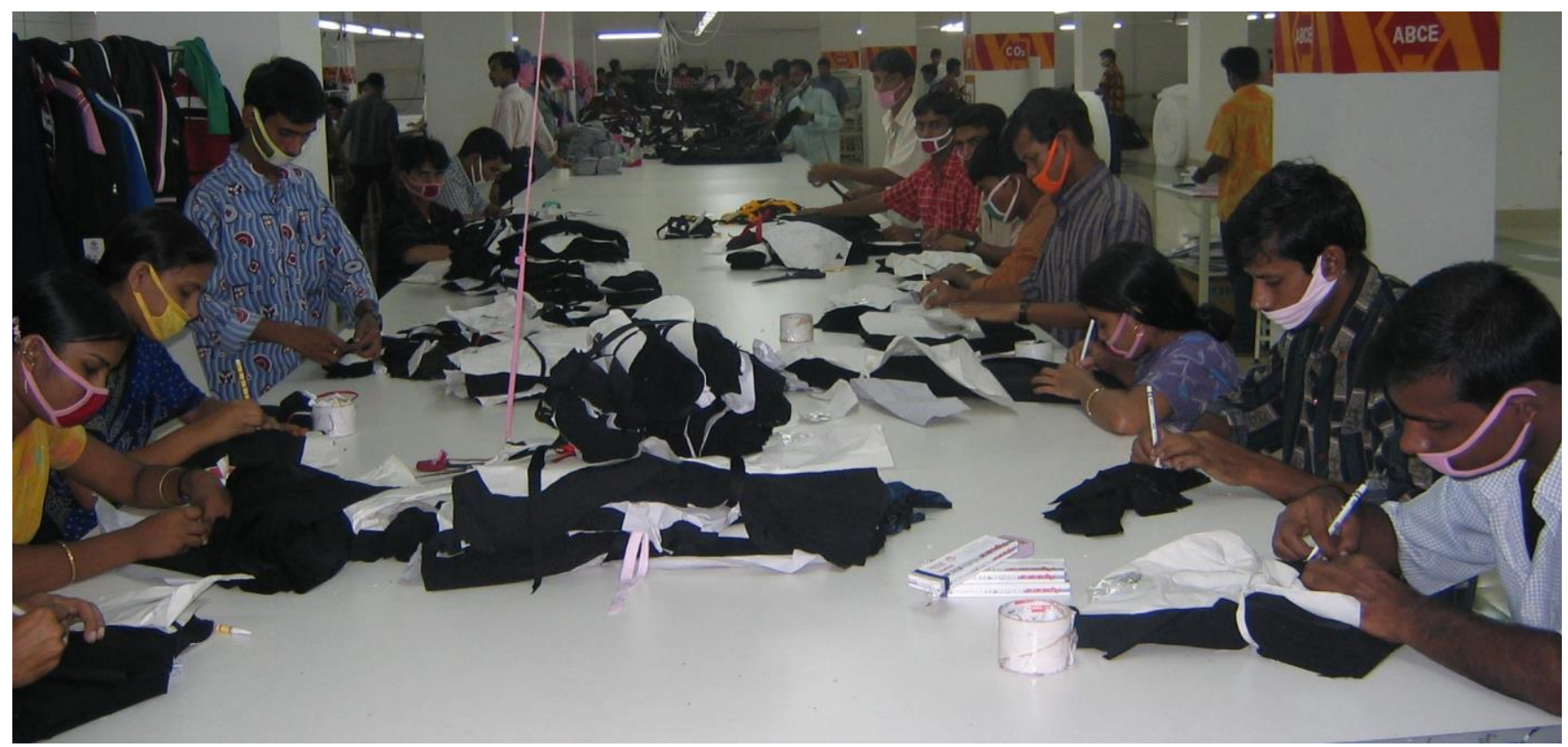


Because men tend to constitute the majority of middle and senior management, company leaders should acknowledge that they likely do not have an understanding of women's health needs and should give special attention to these needs. However, corporate leadership on gender in fact is about addressing the needs of both sexes. Health-related absenteeism for men may be very different from health-related absenteeism for women. Women may miss work because of menstrual pain; men may miss work because of alcohol consumption. The management response to each situation will be different. A rigorous approach to gender includes collecting all productivity and health data differentiated by sex and analyzing it on a regular basis as part of company performance metrics.

The point of the second area is that statements of valuing health - such as placing worker health and wellbeing into values statements and codes - must be backed up by strong policies and accountability. The history of workplace health programs is littered with experiences of top leaders sanctioning a program and declaring its importance but line supervisors undermining programs at every turn. These supervisors do not have bad intentions; rather they gain no personal benefit in having workers spend time engaged in peer education activities or getting care for non-emergencies at health facilities. Few supervisors win bonuses for the healthiest production line. And some may suspect that workers are using health clinics as a way to get an easy break. The CEO needs to gain buy-in from all management levels and lead by example. Senior leadership needs to engage managers on the business case for health and well-being as well as including health metrics in recognition and rewards systems.

Finally, top leadership is essential to changing managers' view of health services from a cost center to a strategic resource. Effective, proactive health providers are doing more than fulfilling legal compliance and improving worker health; they are enabling workers to be more productive. Smart leadership will view the health staff as partners in improving communication, building trust and loyalty and providing essential information for improving the well-being of workers and the productivity of the enterprise.

\section{MANAGEMENT/LEADERSHIP GUIDELINES AND INDICATORS}

\section{MANAGEMENT SYSTEMS}

6.1. MANAGEMENT PROCESSES - Management structures and processes exist for oversight of health services.

\section{Indicators:}

6.1.1. Management aligns responsibility for oversight of health practices and standards to the appropriate senior manager.

6.1.2. A reporting structure for the health facility exists that defines roles, responsibilities, and decision-making authorities.

6.1.3. Each health provider receives a job description defining responsibilities based on standards.

6.1.4. The senior manager reports on progress in meeting the health guidelines and benchmarks twice a year to senior and middle management.

6.1.5. A formal process for hiring new health providers based on the review and documentation of qualifications is in place.

6.1.6. An annual budget for health operations is allocated that is adequate for meeting workplace health guidelines and plans.

6.2 SUPERVISION OF HEALTH SERVICES - Management supervises the health facility and staff and provides necessary support for achievement of annual plans.

\section{Indicators}

6.2.1 The senior manager meets regularly with the health staff to ensure guidelines and plans are being met. 
6.2.2 The senior manager and the health staff develop each year an action plan for health improvement and outreach.

6.2.3 The senior manager reviews each year the guidelines and health plans with any part-time medical staff to ensure their compliance with workplace health policies and practices.

6.2.4 Each health providers' job performance is evaluated against defined goals and responsibilities by the senior manager annually and compensated appropriately.

6.2.5 An external health expert observes the health operations at least every two years to assess compliance with the guidelines and identify areas for improvement.

6.3 INTEGRATION OF HEALTH INTO WORKPLACE OPERATIONS - Health activities are integrated into overall company processes and functions.

\section{Indicators}

6.3.1 General health practices under the guidelines are integrated into existing occupational health and safety practices, policies, and standards.

6.3.2 Management has a process for addressing violence, harassment and threats to women and men workers and it includes an appropriate role for workplace health providers.

6.3.3 The health staff participates in all worker committees and, as appropriate, management committees to engage participants on health issues and activities.

6.3.4 New worker orientation and training programs include introductions to the health providers and infirmary and a briefing on health services, policies and patient rights.

6.3.5 Management seeks the formal input of women and men workers and their representatives in developing the annual health plan each year.

6.3.6 Facility health data is incorporated into overall management data systems for quality, productivity, and occupational safety.

6.3.7 Health data, disaggregated by sex and age, is reviewed at least twice a year by the management team and the appropriate worker committees.

\section{CORPORATE LEADERSHIP}

\subsection{INTEGRATION OF HEALTH INTO ENTERPRISE'S POLICIES, GOALS, AND VALUES - Health and well-being are an explicit part of values statements, codes, and business strategy. \\ Indicators}

7.1.1 Worker health and wellness policies incorporating the guidelines and other occupational health and safety standards are established.

7.1.2 Gender equity in health services (and all other operations) is explicitly written into policies.

7.1.3 Chief Executive Officer communicates annually to managers and workers information on workplace policies, national law and contractual requirements relating to health.

7.1.4 Corporate values or codes statements include commitments to worker health and wellbeing beyond the legal minimum.

7.1.5 Chief Executive Officer establishes and enforces policies that address the specific health issues of migrant workers from other countries.

7.1.6 Chief Executive Officer evaluates health and wellness policies each year with senior and middle managers for gaps, understanding, and workplace performance.

7.1.7 Chief Executive Officer makes a corporate commitment to applying the World Health Organization's Healthy Workplaces model and plan of action. 


\subsection{STRONG ACCOUNTABILITY FRAMEWORK FOR HEALTH - Accountability for}

adhering to policies promoting worker health and well-being at all levels of the enterprise is established.

\section{Indicators}

7.2.1 The manager of health services reports quarterly to the chief executive officer on performance on the health guidelines and related occupational health issues.

7.2.2 Chief Executive Officer makes commitment to improve at least one health area under the guidelines each year.

7.2.3 Chief Executive Officer ensures that the funds for the health line item in the budget are allocated.

7.2.4 Chief Executive Officer uses health data and metrics as part of its annual assessment of enterprise performance and productivity.

7.2.5 Chief Executive Officer communicates formally each year to line and senior managers and workers on the health status of the workforce and its impact on business performance.

7.2.6 Performance reviews of line managers and related compensation takes into account their adherence to workplace health policies, plans and commitments.

7.2.7 The enterprise shares primary health information related to infectious diseases and illness with the public health system (in addition to data on injuries and occupational health events). 


\section{Section 4: Appendices}

\section{APPENDIX A: DEVELOPMENT OF THE GUIDELINES AND RESOURCES USED}

In December 2012, a small roundtable of health and workplace experts in Washington, D.C., was convened to help develop a set of voluntary health guidelines to help companies improve workplace health facilities and practices. It became clear that the guidelines would also need to address management practices if the health practices were to be improved. These guidelines became called the Workplace Health Facility Guidelines and Management Benchmarks as they were envisioned to be adopted voluntarily by multinational corporations and their supply chains as well as be part of workplace policy considerations by governments and international organizations.

The roundtable was organized by the RAISE Health Initiative for Workers, Companies and Communities, as part of the Evidence-to-Action project managed by Pathfinder International. As of October 2014, RAISE Health became a major activity of the Evidence Project managed by the Population Council, both funded by USAID. The roundtable was co-hosted by HERproject, which is a women's health education and empowerment program managed by Business for Social Responsibility.

The development of these guidelines responded to the experience of many of the organizations represented at the roundtable - namely, that health workers in factories and farms in the developing world often did not conform to accepted health practices. Furthermore, in many cases, health providers were underutilized and poorly trained. A set of health guidelines for workplace providers and health facilities was seen as way to help and spur factories and farms to increase access to and provide higher quality services for workers.

There are several challenges for developing health guidelines for workplace health facilities in factories and farms in developing countries:

1. These facilities vary greatly in terms of qualifications of service providers, services provided and quality of the health infrastructure.

2. The facilities are not primary care centers and thus are not required to meet comparable standards.

3. Standards that are onerous or unrealistic given the setting will be ignored by management and thus will not improve quality or practice.

The goal of the group was to establish guidelines that would be relevant to a wide range of workplace health facilities and help establish a process of continual improvement. It was understood that the guidelines would be offered as part of an ongoing and open process to determine the effectiveness and feasibility of health guidelines at the workplace. And they would undergo regular revision as organizations and companies learned from the experience of implementing them.

The role of the group was not to "create" new standards but rather to apply and adapt existing standards, norms, and best practices to the workplace according to these criteria:

- Guidelines establish a minimal or basic level of practice so that they would be relevant to even the smallest factory as well as larger workplaces.

- They are forward leaning with the goal of driving improvement, not simply be a minimum.

- They focus on the most important, feasible, and cost-effective practices in an environment of limited resources and time constraints.

- They cover diverse health practices, including family planning and reproductive health and gender issues. 
- They adopt and adapt accepted best/high impact practices for workplace health clinics.

- They provide guidance for implementation and access to resources.

- They require no specialized health services or theater of operations.

- These are not designed for companies that offer onsite comprehensive primary care services, as these should already be compliant with national and international health regulations.

\section{Development Process}

In preparation for the roundtable, RAISE Health undertook a literature review to identify existing primary care and family planning standards that could be applicable to the workplace, which are listed on the following page:

The project team also held telephone interviews with field representatives of organizations that have workplace health programs:

- Dr. Bobby Joseph, professor and head, Community Health, St. John's Medical College, India

- Asif Uddin Ahmed, director, Private Sector Engagement team, CARE Bangladesh

- Thou Chum, program director, Marie Stopes International Cambodia

- Dr. Issa Wone, University of Dakar School of Medicine, Senegal

The research was compiled in a document and used in the initial deliberations by roundtable participants in December 2012. The purpose of the roundtable was to review existing standards in the context of industrial and agricultural workplaces and propose a framework for drafting the Workplace Health Facility Guidelines.

The group comprised:

- David Wofford, Vice President for Public-Private Partnerships, Meridian Group International, Inc. (RAISE Health)

- Racheal Yeager Meiers, Manager, Business for Social Responsibility, HERproject

- Shawn Malarcher, Senior Advisor for Best Practices in Family Planning, USAID

- Dr. Salwa Bitar, Principle Technical Advisor, Evidence-to-Action project

- Dr. Shawn MacDonald, Director of Programs and Research, Verité

- Meira Neggaz, Senior Program Manager, Maria Stopes International

- Dr. Fabio Castaño, Global Technical Lead on Family Planning and Health, Management Sciences for Health

During 2013, the group's comments were compiled into a list of draft guidelines. BSR with the ILO/IFC Better Work programme held a one-day meeting in Malaysia in June 2013 to review the list and provide further guidance on the proposed guidelines. This meeting included representatives of BSR implementing partner organizations from Bangladesh, China, and Cambodia as well as representatives of RAISE Health and Pathfinder International. Further consultations occurred with Better Work legal staff on laws governing workplace health requirements in the then eight Better Work countries as well as with BSR representatives in Paris.

From these consultations a draft set of guidelines and guidance materials were developed for workplace managers and implementing partners in February 2014. These were reviewed by BSR HERproject leadership as well as its implementing partners in Bangladesh and Kenya. Also Dr. Bobby Joseph of St. John's Medical College provided comments.

BSR also developed an auditing scorecard for its implementing partners and tested its applicability in 10 factories in Bangladesh as well as at a flower farm in Kenya. RAISE Health tested the guidelines in its clinic re-engineering project in Haiti and later in its re-engineering clinic project in the supplier factory in Egypt of a 
major brand. The resulting guidelines represent the latest thinking about policies and practices that are feasible and effective at the workplace.

Input from the individuals and their organizations was used to advise on the feasibility and necessity of guidelines and does not represent formal endorsement by the individuals or their organizations. The standards are designed to be revised or adapted as corporations, supplier companies, NGOs and governments put them in practice over time.

\section{Standards/Policies Reviewed}

The primary development principle for the guidelines was to adapt existing health and workplace standards to industrial and agricultural settings in developing countries. The number of organizations and institutions with assessment tools and standards is enormous. The literature review focused on a targeted group of organizations within the global health and reproductive health fields as well as corporate codes and policies. The initial literature review took place in fall 2012 but continued throughout the development process:

\section{WORLD HEALTH ORGANIZATION}

Building Healthy and Equitable Workplaces for Women and Men: A Resources for Employers and Worker Representatives, Protectings Worker's Health Series No. 11, WHO 2011

Connecting Health and Labour: Bringing together occupational health and primary care to improve the health of working people, Executive Summary of Global Conference "Connecting Helath and Labour: What Role for Occupational Health in Primary Health Care" (The Hague, the Netherlands 29 November-1 December 2011), WHO 2012

Gender, Work and Health, WHO, 2011. http://www.who.int/occupational health/publications/gender work health/en/

Essential Health Packages: What Are They For? What Do They Change? WHO Service Delivery Seminar Series, Draft Technical Brief No. 2, July 3, 2008, World Health Organization.

WHO Healthy Workplace Framework and Model: Background Document and Supporting Literature and Practices, World Health Organization, 2010. http://www.who.int/occupational health/healthy workplaces/en/

OptimizeMNH, (online interactive guide), WHO. This guide provides a scope of work for a variety of health workers from lay health workers, auxiliary nurse/midwife, nurse/midwife, associate clinicians, and non-specialist doctors. http://optimizemnh.org/intervention.php

Hand Hygiene in Outpatient and Home-based Care and Long-term Care Facilities: A Guide to the Application of the WHO Multimodal Hand Hygiene Improvement Strategy and the "My Five Moments for Hand Hygiene” Approach, WHO 2012

THE WORLD BANK/INTERNATIONAL FINANCE CORPORATION (IFC)/INTERNATIONAL MONETARY FUND (IMF)

Introduction to Health Impact Assessment, IFC Good Practice Publications, International Finance Corporation, 2009

http://www.ifc.org/wps/wcm/connect/a0f1120048855a5a85dcd76a6515bb18/HealthImpact.pdf?M OD=AJPERES

Self-Assessment Guide for Health Care Organizations, International Finance Corporation (includes the IFC Code of Conduct for Health Care Organizations) 
http://www1.ifc.org/wps/wcm/connect/Industry_EXT_Content/IFC_External_Corporate_Site/Industries $\angle$ Health + and + Education/Health + Sector/PromotingHC + Standards/

Women, Work, and the Economy: Macroeconomic Gains from Gender Equity, IMF Discussion Note, IMF, September 2013.

Workers' Accommodation: Processes and Standards, a guidance note, European Bank for Reconstruction and Development and International Finance Corporation, 2009

\section{USAID/USAID-FUNDED HEALTH ORGANIZATIONS}

Balanced Counseling Strategy: A Toolkit for Family Planning Service Providers, León, Federico, Ricardo Vernon, A. Martin and L. Bruce. Population Council, 2008.

http://www.popcouncil.org/uploads/pdfs/frontiers/Manuals/BCS/BCS_UsersGuide.pdf

Community Health Workers: Bringing family planning services to where people live and work, High Impact Practices, USAID, 2011.

https://www.fphighimpactpractices.org/sites/fphips/files/hip_chw brief.pdf

Family Planning High Impact Practices (website), USAID. https://www.fphighimpactpractices.org/

Standards-Based Management and Recognition: A Practical Approach for Improving the Performance and Quality of Healthcare (A field guide), Edgar Necochea and Débora Bossemeyer, JHEIPGO, 2005 http://www.jhpiego.org/files/SBMR\%20FieldGuide.pdf

Strenghtening Quality Assurance in Primary Health Care in the Republic of Armenia: Quality Assurance Toolkit, M.Kirakosyan and M.Segal, Primary Health Care Reform Project, USAID/Armenia, 2008.

\section{INTERNATIONAL LABOR ORGANIZATION (ILO)}

Analysing Better Work Data from a Gender Perspective: A Prelimary Exploration of Worker Surveys with a Focus on Vietnam, Better Work Discussion Paper Series No. 13, M. Fontana and A. Silberman, Better Work programme, ILO/IFC, December 2013. http://betterwork.org/global/wp-content/uploads/DP13.pdf

Do Factory Managers Know What Workers Want? Manager Worker Information Asymmetries and Pareto Optimal Working Conditions, Better Work Discussion Paper Series No. 13, M. Fontana and A. Silberman, Better Work programme, ILO/IFC, June 2013

http://siteresources.worldbank.org/EXTNWDR2013/Resources/8258024-1320950747192/8260293$1320956712276 / 8261091-$ 1348683883703/WDR2013 bp_Do_Factory_Managers_know_what_Workers_Want.pdf

Fundamental Principles of Occupational Health and Safety, B.O. Alli, International Labour Office Geneva, ILO, 2008

http://www.ilo.org/wcmsp5/groups/public/@,dgreports/@dcomm/@publ/documents/publication/wcms 093550.pdf

International Labors Standards on Occupation Health and Safety, (ILO website), International Labour Organization. http://ilo.org/global/standards/subjects-covered-by-international-labour-

standards/occupational-safety-and-health/lang--en/index.htm 
The Community Score Card (CSC): A generic guide for implementing CARE's CSC process to improve quality of services, CARE Malawi, Cooperative for Assistance and Relief Everywhere, 2013.

NICE (National Institute of Health for Clinical Excellence) Standards: NICE outlines a multitude of clinical guidelines, mostly concerning basic mental and physical illnesses. The standards of interest concern antenatal care and pregnancy. These are basic recommendations for primary care physicians and clinic workers. http://www.nice.org.uk/guidance/qualitystandards/qualitystandards.jsp

Healthy Employees in Healthy Organizations, ENWHP Toolbox, A European Collection of methods and practices for promoting health at the workplace, European Network for Workplace Health Promotion, April 2004.

International Essentials of Health Care Quality and Patient Safety, Joint Commission International, 2010. http://www.mtpinnacle.com/pdfs/international-essentials(1).pdf

Quality Care for Integrated Services: A Facility Assessment Tool, Pathfinder International, 2000. http://www.pathfinder.org/publications-tools/Quality-of-care-for-Integrated-Servicse-A-FacilityAssessment-Tool.html

SafeCare Health Standards. These standards represent the adaptation for low-resource settings of accepted health care standards, including the Joint Commission International's "International Essentials of Health Care Quality and Patient Safety Standards." (Safe Care was created by the PharmAccess Foundation of the Netherlands, the Joint Commission International (JCI) of the U.S.A and the Council for Health Service Accreditation of Southern Africa (COHSASA). http://www.safe-care.org/index.php?page=safecare$\underline{\text { standards }}$

The Training Resource Package for Family Planning (website), an initiative led by $\underline{\text { USAID }}$, WHO, and UNFPA, with full participation from technical and training experts representing multiple agencies and organizations including Centers for Disease Control (CDC), International Planned Parenthood Foundation (IPPF), and USAID implementing partners EngenderHealth, FHI 360, the Institute for Reproductive Health, IntraHealth, Jhpiego, The Johns Hopkins University, Management Sciences for Health, and Pathfinder International. Pathfinder International serves as the current secretariat. http://www.fptraining.org/

The SEED Assessment Guide for Family Planning Programming, EngenderHealth, 2011. http://www.engenderhealth.org/pubs/family-planning/seed-assessment-guide-for-family-planning.php 


\section{APPENDIX B: DEFINITIONS}

Workplaces vary widely in the types of health facilities, services and providers they have on-site. These facilities and the health services they provide differ from primary health services in the public sector. Yet the guidelines aim to help companies ensure that workers have access to primary health services - as available in and relevant to the local circumstances - whether at the workplace or off-site or, in many cases, through a combination of the two.

The guidelines are based on the World Health Organization's definition of a healthy workplace:

"A healthy workplace is one in which workers and managers collaborate to use a continual improvement process to protect and promote the health, safety and well-being of workers and the sustainability of the workplace by considering the following, based on identified needs:

- health and safety concerns in the physical environment;

- health, safety, and well-being concerns in the psycho-social work environment, including organization of work and workplace culture;

- personal health resources in the workplace; and

- Ways of participating in the community to improve the health of workers, their families and other members of the community." ${ }^{\mathrm{x} i}$

Below are additional definitions related to the provision of services:

\section{Health facility refers to:}

- Health station/stop (lowest level), usually in or near the production site - managed by a nurse or lesser trained health staff providing care for small injuries and making referrals for more specialized care.

- Nurse-staffed health clinic/infirmary - managed by a nurse providing basic health information and care for injuries.

- Basic health center - managed by a clinical officer usually with a nurse and providing general health services.

- Primary health center - consisting of a medical doctor, nurse and lab technician offering minor surgery and chronic diseases management as well as general health services.

- Hospital (bighest level).

Workplaces facilities tend to fall within the first three categories, although the services provided may not fit exactly as one would expect for as specific category. For instance, in many cases, workplaces contract with doctors to visit their facility on a part-time basis.

For the purpose of the guidelines, the term "bealth facility" refers to any kind of physical location on-site that is dedicated to the provision of worker health services.

\section{Health provider refers to:}

- Community health worker/designated health officer - this person has minimal, if any, formal training in health and may have less than a $10^{\text {th }}$ grade education.

- Nurse assistant - this person has limited formal training, but has had the experience of assisting qualified personnel in a health-care setting.

- Paramedic

- Nurse (the level of training and certification varies widely from country to country)

- Clinical officer

- Doctor 
Factories and workplaces at the lowest level employ the equivalent of a community health worker who is able to treat a minor injury, provide limited health or safety information, and refer injured workers to an external health facility.

For the purpose of the guidelines, the term "bealth provider" or "provider" will be used to refer to all personnel that is hired or contracted by a company to provide any level of health services at the workplace.

\section{Health services refer to:}

"All services dealing with the diagnosis and treatment of disease, or the promotion, maintenance and restoration of health." (World Health Organization) Various organizations have defined these further to include:

- Diagnosis of illness

- Preventive and curative health measures

- Medical record-keeping

- Evacuation of the wounded, injured, or sick

- Blood management

- Medical supply, equipment, and maintenance thereof; combat stress control and

- The dispensing of medicine or prescription of a drug or medicinal preparation by a pharmacist

- Dental, laboratory, optometric, medical food services"

Similarly, using the Declaration of Alma-Ata, International Conference on Primary Health Care, primary health cares services refer to:

"Providing promotive, preventative, curative, and rehabilatory services, and "Includes at least:

- Education concerning prevailing health problems and the methods of preventing and controlling them

- Promotion of food supply and proper nutrition

- An adequate supply of safe water and basic sanitation

- Maternal and child health care, including family planning

- Immunizations against the major infectious diseases

- Prevention and control of locally endemic diseases

- Appropriate treatment of common diseases and injuries and

- Provision of essential drugs."

The kinds and level of services vary widely among workplaces. Most workplaces provide at minimum health services limited to occupational health norms of curative care for minor injuries and evacuation to hospitals or primary care facilities for serious injuries. Many provide additional on-site services for specific diseases, such as HIV/AIDS, tuberculosis or malaria, and have health education programs related to them. Some provide a much larger range of services and health education on-site.

Most national laws have standards for occupational health and safety and require workplaces to keep records of workplace accidents and workplace related diseases. These standards take precedence in the unlikelihood of conflict with the guidelines, which are designed to complement Occupational Health standards and fit into existing occupational health components within a company.

For the purpose of the guidelines, the term "health services" refers to any of the activities that fall under the WHO and Alma Atta definitions above. 


\section{APPENDIX C: HEALTHY WORKPLACE MODEL (WORLD HEALTH ORGANIZATION)}

Below are excerpts from the "WHO Healthy Workplace Framework and Model: Background and Supporting Literature and Practice," which has been reprinted with the permission of WHO. .ii $^{\text {This document provides }}$ background on the effort to look more broadly at the health needs of workers and in-depth guidance on implementation. The permission to reprint sections of this document does not represent endorsement of the Workplace Health Facility Guidelines and Management Benchmarks by WHO.

\section{CHAPTER 1: WHY DEVELOP A HEALTHY WORKPLACE FRAMEWORK?}

In 1995, the World Health Assembly of the World Health Organization endorsed the Global Strategy on Occupational Health for All. The strategy emphasized the importance of primary prevention and encouraged countries with guidance and support from WHO and ILO to establish national policies and programmes with the required infrastructures and resources for occupational health. Ten years later, a country survey revealed that improvements in healthy workplace approaches were minimal and further improvement was required. In May 2007, the World Health Assembly endorsed the Global Plan of Action on Workers Health (GPA) for the period 2008-2017 with the aim to move from strategy to action and to provide new impetus for action by Member States. This watershed document was the culmination of numerous other meetings on occupational health that are outlined in Chapter 2. The GPA takes a public health perspective in addressing the different aspects of workers' health, including primary prevention of occupational risks, protection and promotion of health at work, work-related social determinants of health, and improving the performance of health systems. In particular, it set out five objectives:

- Objective 1: To devise and implement policy instruments on workers' health

- Objective 2: To protect and promote health at the workplace

- Objective 3: To promote the performance of and access to occupational health services

- Objective 4: To provide and communicate evidence for action and practice

- Objective 5: To incorporate workers' health into other policies.

It is clear that all of these objectives are linked and overlap, as they should. For example, in order to protect and promote health at work" (Objective 2) it is necessary to have policy instruments on workers' health at the national and enterprise level (Objective 1) and for workers to have access to occupational health services (Objective 3), and for all this to be backed up by the best scientific evidence (Objective 4). In addition, workers' health must be integrated into educational, trade, employment, economic development and other policies (Objective 5) in order to truly protect and promote workers' health (Objective 2).

\section{CHAPTER 9: "THE WHO HEALTHY WORKPLACE FRAMEWORK AND MODEL"}

Process for Implementing a Healthy Workplace Programme. Implementing a healthy workplace programme that is sustainable and effective in meeting the needs of workers and the employer requires more than knowing what kinds of issues to consider, as are outlined above in the four avenues of influence. To successfully create such a healthy workplace, an enterprise must follow a process that involves continual improvement, a management systems approach, and which incorporates knowledge transfer and action research components.

The process recommended by WHO is based on an adaptation of WPRO's Regional Guideline. It is a cyclic or iterative process that continually plans, acts, reviews and improves on the activities of the programme. It is graphically represented in Figure 9.2. 
Two of the core principles are leadership engagement based on core values and ethics, and worker involvement. These are not merely steps in the process, but are ongoing circumstances that must be tapped into at every stage of the process.

\section{Figure 9.2 WHO Model of Healthy Workplace Continual Improvement Process}

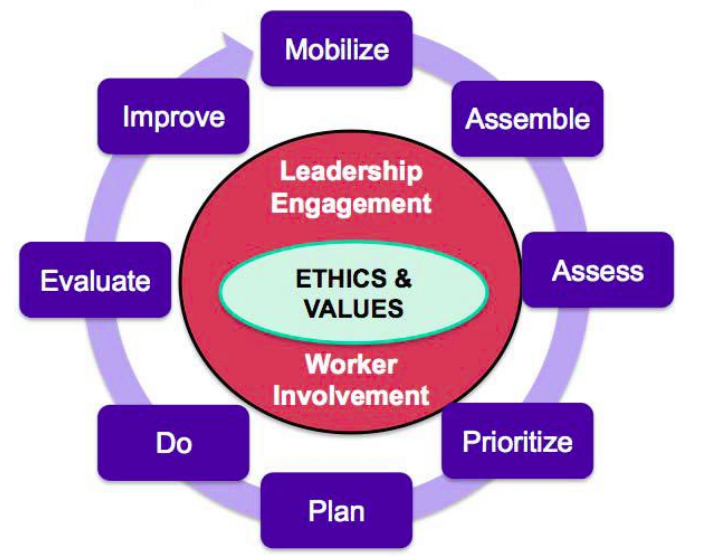

\section{Mobilize}

In Chapter 7 we noted that it is critical to mobilize and gain commitment from the major stakeholders and key opinion leaders in the enterprise and community before beginning. If permission, resources, or support are required from an owner, senior manager, union leader, or informal leader, it is important to get that commitment and buy-in before trying to proceed. This is an essential first step.

It should be recognized that sometimes in order to mobilize key stakeholders to invest in change, it is necessary to do some up-front information collection. People hold different values and operate in differing ethical frameworks. They are motivated and mobilized by different things - by data, or science, or logic, or human

stories, or conscience, or religious beliefs. Knowing who the key opinion leaders and influencers are in an enterprise, and what is likely to mobilize them, will assist in gaining this commitment.

The term "mobilize" is used here deliberately. This step is about more than just getting an "OK" from the owner. Key evidence of this commitment is the development and adoption of a comprehensive Policy that is signed by the highest authority in the enterprise and communicated to all workers and their representatives. Additional evidence is the engagement of the key leaders in mobilizing resources for change - providing the people, time and other requirements for making a sustainable improvement in the workplace.

While getting initial indications of management commitment is part of this Mobilize step, leadership engagement must continue to be demonstrated and apparent from the key stakeholders at every step of the process, hence its key placement graphically at the core of the circular process.

For a detailed example of how to implement this and the subsequent steps in the process in both a large corporation and in a small enterprise in a developing nation, refer to Table 9.1.

\section{Assemble}

Once the key stakeholders have been mobilized and their enthusiastic commitment provided, they will be able to demonstrate this commitment by providing resources. This is the time to assemble a team who will work on implementing change in the workplace. If there is an existing health and safety committee, that preexisting group may be able to take on this additional role. One caution is that in countries with legally mandated safety and health committees, there are often numerous legislated requirements that the OSH committee must perform, and these tasks would take precedence over other, broader healthy workplace activities. Often (in a larger enterprise) it is better to set up a separate committee, as long as steps are taken to ensure that there is integration between the committees (see Chapter 7, Section D, The Importance of Integration.) For the purposes of this document, we will call this the Healthy Workplace Team, with the understanding that in some circumstances it could be a pre-existing committee with other functions.

In a large enterprise, this Healthy Workplace Team should include representatives from various levels and sectors of the business, and may include health and safety professionals, human resource personnel, 
engineers, and any medical personnel who provide services. It is critical to have representation from the trade union(s) if applicable, and in any case to have at least half the members be non-management employees.

It is also critical to have equitable gender representation on this Team. As noted frequently in this document, women face unique and serious health, safety and well-being risks in workplaces, and their voices must be heard at every stage when creating a healthy workplace. It is not enough to add a "token woman" on the team; women should be present in equal numbers to men, ideally, or in numbers that reflect the makeup of the enterprise's workforce. If no women work in the enterprise, that in itself may be an indication that there is probably employment discrimination occurring, which should be addressed as a priority.

In a small enterprise, it is helpful to involve experts or support personnel from outside the organization if possible. For example, medical personnel from a neighbouring large enterprise or community occupational health clinic, a representative from a local industry-specific network, or from a local health and safety agency may be invaluable.

As well as assembling the Team, this is a good time to assemble other resources that will be required. Ensuring that space to meet, time to meet during work hours, a budget, and minimal working supplies are provided will mean the committee has the resources necessary to do the work.

\section{Assess}

The first set of tasks that the Healthy Workplace Team should perform falls under the heading of "assessments." There are two broad categories of things that need to be assessed: (1) the present situation for both the enterprise and the workers, and (2) the desired future conditions and outcomes for both the enterprise and workers.

The present situation for the enterprise can be assessed using a number of different tools, depending on the size and complexity of the organization. In a large corporation, baseline data should be collected on employee demographics, sickness injury data, workplace related injuries and illnesses, short-term and long-term disability, turnover, union grievances if applicable, and concerns that have arisen from workplace inspections or hazard identification \& risk assessment processes. Productivity data should also be documented as a baseline, if it is available. If a comprehensive hazard identification \& risk assessment has not been done, it should be done at this time. Current policies or practices relating to any of the four avenues of influence should be reviewed and tabulated (for example, take note if there are policies related to flexible work hours, volunteer time, or fitness club subsidies.)

In addition to assessing the present situation of the enterprise, it is necessary to assess the present situation with respect to the health of workers. In a large enterprise, this will require a confidential survey and/or health risk assessments. In the case of a survey, it is important to ask questions related to the four avenues of influence. That means asking questions about the organizational culture leadership issues, workplace stress, non-work-related sources of stress, and personal health practices, as well as their concerns about the hazards they are exposed to in their physical work environment or in their community.

In an SME, this assessment may be a walkthrough with a simple checklist, and some small group discussions with workers and their representatives. See Table 9.1 for more suggestions.

The desired future for the enterprise and workers must also be assessed. For a large corporation, this may involve some standarding exercises to determine how similar companies are doing with respect to the data just described. It may be important to do a literature review to read case studies of good practice, or recommendations for good practice. For individual workers, it is necessary to ask for their thoughts and opinions about what they would like to do to improve their working environment and health, and what they think the employer could do to assist them. 
For a small enterprise, determining local good practice is important. Talking to local experts or visiting local enterprises that have addressed similar situations is a good way to find out what can be done, and get ideas on how to do it.

The Western Pacific Regional Office's Regional Guidelines for the Development of Healthy Workplaces suggests the following methods of data collection:

- review of documents - inspection reports, accident and injury statistics, safety audits, absenteeism data, etc.;

- walk-through inspection - to identify hazards and potential health risks in the physical environment;

- environmental monitoring and health/medical surveillance - with the assistance of experts in occupational hygiene and medicine, it is possible to obtain data about physical and chemical agents in the workplace and the amount of worker exposure;

- written survey - a confidential and anonymous survey, either on paper or delivered electronically, to ask about the issues discussed above;

- focus group discussion - small group meetings facilitated by a leader with specific objectives in mind and structured questions. These are particularly useful in small enterprises or with groups of workers with low literacy. Focus groups are also useful to flesh out, or validate information obtained from a written survey.

- Interviews - more in-depth, face-to-face interviews may be held with key stakeholders or professionals;

- suggestion box - a way of soliciting anonymous suggestions, which may be more candid than opinions ventured in a group discussion.

Whatever methods are used to collect this information, it is important to make sure that women have as much opportunity for input as men. Survey instruments should be confidential and anonymous, but should collect information regarding the sex of the participant, so that the information collected can be analyzed separately, to tease out issues that are more important to one gender than the other. If information is collected from focus groups, it is essential to provide a safe setting for women to freely voice their opinions, and not feel intimidated by male workers. In addition, men may sometimes feel reluctant to express their fears or concerns in a mixed gender group.

\section{Prioritize}

Once all the information has been collected, the Healthy Workplace Team must set priorities among the many issues identified, since there will possibly be too many problems to deal with all at once. If the enterprise is small and the number of significant issues is low $(\sim 5-10)$ then the employer and workers can probably use a relatively simple approach to choose the top items to deal with first.

Before attempting to set priorities, however, it is wise to discuss and agree upon the criteria to be used in making decisions about priorities. How will a decision be made as to which is more important - providing respirators for workers doing sand-blasting, or eliminating racial harassment from the workplace? In making these decisions, there are two critical things to take into consideration:

1. the opinions and preferences of the workplace parties, including managers, workers and their representatives; and

2. the position on Maslow's hierarchy of needs.

The first point is of paramount importance, but potentially dangerous if workers and their representatives are not knowledgeable enough about the risks to make informed decisions. This reinforces the importance of training and learning from others, which is discussed in Chapter 7. 
The second point refers to a system of ranking human needs proposed by Abraham Maslow, which is often characterized as illustrated in Figure 9.3. Clearly, it is important to deal with issues closer to the base of the pyramid before worrying about those higher up. In most cases, problems related to physical safety and health are more basic and immediately threatening than those concerned with mental health and well-being, which is why countries usually develop legislation in this area first. Put crudely, inhaling silica in the workplace will kill a worker much more quickly than experiencing demeaning racial harassment will, although both are very unhealthy.

Other criteria that may be considered are:

- how easy it would be to implement a solution to the problem (consider "quick wins" that may motivate and encourage continued progress);

- the risk to workers (this is a combination of the severity of the exposure to the hazard and the probability that it will occur);

- the possibility of making a difference (including the existence of effective solutions to the problem, readiness of the employer to make a change, or the likelihood of success);

- the relative cost of the problem if it is ignored;

- "political" considerations (this may include actual issues related to

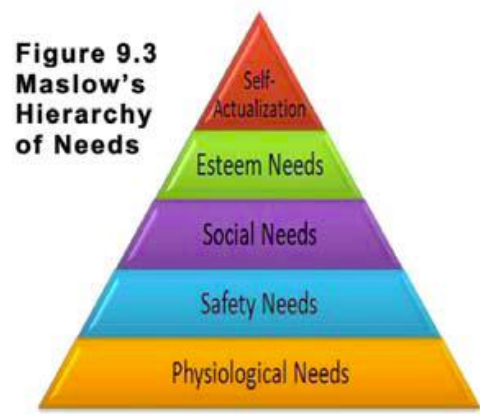
the political situation in a country or community, or so-called "internal politics" issues related to enterprise power and influence.

Once agreement on the criteria has been reached there are various ways to select priorities. One way is simply to list all the problems and let everyone choose their top three. Then total the numbers for each item and see how the ranking falls out. Another method is to categorize each of the problems as (a) important and urgent; or (b) urgent but not important; or (c) important but not urgent. Put the A items at the top of the list and plan for the group to address them first, in consultation with the owner/operator of the enterprise. Ask for a volunteer with some authority who can accept WHO Healthy Workplace Framework and Model:

Background Document and Supporting Literature and Practices 100 Chapter 9: The WHO Healthy Workplace Framework and Model responsibility for doing the B items right away. Then make a plan for the team to do the $\mathrm{C}$ items after $\mathrm{A}$ and $\mathrm{B}$ have been done. If there are any items on the list that are considered unimportant and not urgent, they can be removed from the list.

In larger corporations or in complex work situations, there may be too many items to deal with by these simple methods, and a more complex priority-setting process may be required. To make decisions as objectively as possible a ranking system and priority grid may be used to quantify preferences.

When setting priorities, it is wise to provide opportunities to determine if there are different priorities for women than for men. Care should be taken to ensure that priorities for both genders are addressed. The ILO notes that "research provides compelling arguments for the consideration of women's and men's biological differences, in order to ensure that the workplace is adapted to the physical aspects and capacities of both sexes; the findings seem to have been ignored."

\section{Plan}

The next big step is to develop a health plan. In a large enterprise, this would be a "big picture" plan for the next 3-5 years. This will set out the general activities to address the priority problems, with broad timeframes. If additional permission is required from senior leaders to go forward, then the rationale and supporting data for each recommendation should be included in the plan to ensure their support. In the overall plan, the Healthy Workplace Team may not yet have the details of the actions to be taken, and may include items such as "develop and implement a programme to increase worker physical activity" without yet knowing the 
details. The overall plan should have some long-term goals and objectives set, so that in the future it will be possible to determine if there has been success.

After developing the long-term plan, an annual plan would be developed to address as many of the higher priority items as can be handled in the first year. An annual plan would be done for each of the 3-5 years of the overall plan, although these do not need to all be done at the outset.

When considering solutions to the priority problems, it is important to again remember the "Learn from Others" principle, and research ways of solving the problem. At this time, it is extremely important to remember the four avenues of influence. A common mistake made by enterprises is to think that solutions for a problem in the physical work environment must be physical solutions, for example. Recalling the information in Chapter 4 about the way physical and mental health are interrelated, it is critical to consider all four avenues when designing solutions for any one problem. For example, if there is a problem with workers' risking amputation from unguarded machinery (a problem in the physical environment), it is not enough to simply place guards on the machine (a physical solution.) Consideration must also be given to psychosocial factors such as workload, or an organizational culture that places productivity before safety; if these are not considered, workers will probably remove the guards in order to work faster.

After obtaining any additional required approval in principle for the 3-5 year plan, it is time to develop specific programme or policy action plans for the first annual plan. This is where the detail is spelled out for each programme or policy that is to be implemented. For health education programmes, it is important to ensure that they go beyond just raising awareness to include skill development and behaviour change. The required budget, facilities and resources would be included in an action plan, as well as planning for a launch, marketing and promotion of the programme or policy and training for any new policy. Something often forgotten is to include a maintenance plan for 3-5 years, and an evaluation plan for each initiative. Ensuring that each initiative has clearly stated measureable goals and objectives will make evaluation easier in the future.

The plan developed for an SME will probably be much simpler, depending on the size and complexity of the enterprise. It may just be a short list of initiatives to be addressed with an indication of time frames. See Table 9.1 for more ideas.

\section{Do}

As the shoe company motto goes, this is the "Just Do It!" stage. Responsibilities for each action plan should be assigned in the plan, and at this stage it is just a matter of implementing the action plans. Again, it is critical to involve workers and their representatives at this stage, as in other stages. Having management demonstrate their support and commitment for the specific programmes or policies will also help them be successful. Some research has found that integrating the "stages of change" model into implementation is helpful, since not everyone will be at the same stage of readiness for change.

\section{Evaluate}

Evaluation is essential to see what is working, what is not, and what are the impediments to success. Both the process of the implementation and the outcomes should be evaluated, and there should be short-term and long-term outcome evaluations. Since each action plan includes an evaluation component, these evaluation plans can be implemented. In addition to evaluating every specific initiative, it is important to evaluate the overall success of the Healthy Workplace Programme after 3-5 years, or after a significant change, such as a change of managers. Sometimes repeating the same survey, or looking again at the kind of data collected as a baseline can provide this overall assessment. 
While it is unlikely that the changes to worker health will be able to be causally linked to changes in enterprise productivity or profitability, it is important to track these numbers as well, and compare to Standards. For example, if the insurance costs for health benefits in your enterprise keep increasing, even after implementing healthy workplace programmes, that does not necessarily mean the programmes have failed. Look at industry Standards for comparison. If health insurance costs have increased by $20 \%$ in similar industries, yet have only increased by $5 \%$ in your enterprise, that is an indicator of success. More information on returns-oninvestment (ROI) is provided in Chapter 5. 
TABLE 9.1 Application of WHO Continual Improvement Process in Large and Small Enterprises

\begin{tabular}{|c|c|c|}
\hline STEP & LARGE CORPORATION & SMALL ENTERPRISE \\
\hline Mobilize & $\begin{array}{l}\text { - Get buy-in from the senior management team } \\
\text { and trade union leaders or other worker } \\
\text { representatives. } \\
\text { - Ensure that a comprehensive health, safety and } \\
\text { well-being policy is in place. } \\
\text { - Ensure that worker health and well-being is } \\
\text { mentioned in the mission or vision of the } \\
\text { corporation. } \\
\text { - Ensure that resources and an annual budget } \\
\text { have been allocated for healthy workplace } \\
\text { activities }\end{array}$ & $\begin{array}{l}\text { - Explain the healthy workplace concept to the } \\
\text { owner or operator and get permission to } \\
\text { proceed. } \\
\text { - Get permission to hold short meetings with the } \\
\text { workers to determine needs and ideas for } \\
\text { solutions. } \\
\text { - Get a commitment for enough time to plan and } \\
\text { implement programmes. } \\
\text { - Help the owner/operator to develop a short } \\
\text { health and safety/well-being Policy statement } \\
\text { that can be signed and posted in the workplace. }\end{array}$ \\
\hline Assemble & $\begin{array}{l}\text { - Set up a committee of } 10-15 \text { people } \\
\text { representing different departments and work } \\
\text { locations. } \\
\text { - Develop terms of reference. } \\
\text { - Set up regional subcommittees if the } \\
\text { corporation has many sites. } \\
\text { - Ensure cross-representation with the joint } \\
\text { management-labour occupational health and } \\
\text { safety committee. }\end{array}$ & $\begin{array}{l}\text { - Ask for } 2-3 \text { volunteers to help with the work } \\
\text { (the Healthy Workplace Working Group). } \\
\text { - If there are very different types of jobs in the } \\
\text { company (e.g., drivers and labourers) try to get } \\
\text { one of each to help. } \\
\text { - If you can find experts from larger enterprises or } \\
\text { community associations willing to help, include } \\
\text { them. } \\
\text { - Find a space to meet and gather together any } \\
\text { materials you will need. }\end{array}$ \\
\hline Assess & $\begin{array}{l}\text { - Gather demographic data about the workforce, } \\
\text { baseline data on absenteeism, short and long- } \\
\text { term disability, and turnover. } \\
\text { - Conduct a confidential comprehensive survey } \\
\text { of all staff asking about their health status, their } \\
\text { health, safety and well-being concerns, sources } \\
\text { of stress in the workplace or at home, } \\
\text { leadership, employee engagement, etc. } \\
\text { - In the survey, ask what they would like to do as } \\
\text { individuals to improve their health, and how } \\
\text { they think the employer could help. } \\
\text { - Do a comprehensive audit to assess all hazards } \\
\text { and risks in the workplace; or review results of } \\
\text { regular workplace inspection reports. }\end{array}$ & $\begin{array}{l}\text { - If possible (and deemed necessary), find a way } \\
\text { for the Working Group to learn about health, } \\
\text { safety and well-being as it relates to your } \\
\text { industry. } \\
\text { - Obtain a checklist from WHO, ILO, EU- } \\
\text { OSHA, or make one up yourself, and do a walk- } \\
\text { through of your workplace, looking for hazards. } \\
\text { - Determine local good practice and consult } \\
\text { outside experts as appropriate. } \\
\text { - Hold a meeting of all workers. Ask the } \\
\text { owner/operator to start the meeting by assuring } \\
\text { them of his/her commitment to the healthy } \\
\text { workplace concept. } \\
\text { - Lead a discussion with the workers about their } \\
\text { health, safety and well-being concerns. Include } \\
\text { family and community concerns as they relate to } \\
\text { work. } \\
\text { - Brainstorm ideas on what the employees and the } \\
\text { employer could do to make things better. } \\
\text { - Be sure to ask about stress-related concerns as } \\
\text { well as physical concerns. } \\
\text { - Have the Working Group meet with the } \\
\text { owner/operator separately to ask for his/her } \\
\text { ideas on the same topics. }\end{array}$ \\
\hline
\end{tabular}




\begin{tabular}{|c|c|c|}
\hline Prioritize & $\begin{array}{l}\text { - Analyze the results of the survey and } \\
\text { audit/inspection results. } \\
\text { - Prioritize by pairing high need areas with high } \\
\text { "want" areas from employees. }\end{array}$ & $\begin{array}{l}\text { - Do this at the same time as the initial meeting if } \\
\text { possible or at a subsequent meeting. } \\
\text { - List problems and solutions and ask people to } \\
\text { choose their top 3-5. }\end{array}$ \\
\hline Plan & $\begin{array}{l}\text { - Develop a broad 3-5 year plan. } \\
\text { - Develop annual plans with detailed action plans } \\
\text { for each specific activity, programme or new } \\
\text { policy. } \\
\text { - Base action plans on stages of change when } \\
\text { appropriate. } \\
\text { - Include activities addressing awareness, } \\
\text { knowledge and skill-building, behaviour change, } \\
\text { and environmental/organizational adjustments. } \\
\text { - In each specific action plan, include process } \\
\text { and outcome goals as well as evaluation plans, } \\
\text { timelines, budgets and maintenance plans. }\end{array}$ & $\begin{array}{l}\text { - Plan some short-term activities to address } \\
\text { smaller projects or immediate high priority } \\
\text { needs. } \\
\text { - Again, local good practice can be a guide. } \\
\text { - Develop a long-term plan to accomplish bigger } \\
\text { projects. } \\
\text { - Use ideas from the Working Group as well as } \\
\text { other employees or other enterprises. } \\
\text { - Write out the plan and make a list of what you'll } \\
\text { need to accomplish each activity, and present to } \\
\text { the owner/operator for approval or negotiation. } \\
\text { - Plan to do one thing at a time. }\end{array}$ \\
\hline Do & $\begin{array}{l}\text { Divide responsibilities among those on the } \\
\text { committee. } \\
\text { - Hold monthly or bimonthly meetings to assess } \\
\text { progress on all projects }\end{array}$ & $\begin{array}{l}\text { - Carry out the action plans with assistance from } \\
\text { the owner/operator and the Working Group }\end{array}$ \\
\hline Evaluate & $\begin{array}{l}\text { Measure the process and outcome of each } \\
\text { activity against the evaluation plans. }\end{array}$ & $\begin{array}{l}\text { - At a pre-determined time after beginning a } \\
\text { project or initiative, repeat the walk through } \\
\text { inspection to see if previous deficiencies have } \\
\text { improved. } \\
\text { - Ask workers if they think the project worked, } \\
\text { why or why not, and what could be improved }\end{array}$ \\
\hline Improve & $\begin{array}{l}\text { - On at least an annual basis, re-evaluate the 3-5 } \\
\text { year plan and update it. } \\
\text { - Repeat the survey every } 2 \text { years and monitor } \\
\text { changes over time. } \\
\text { - Develop annual plans on the basis of the } \\
\text { evaluations from the previous year. }\end{array}$ & $\begin{array}{l}\text { - Based on what you see and hear from workers, } \\
\text { change the programme to improve it. } \\
\text { - Begin on another project, based onyour list of } \\
\text { priorities. }\end{array}$ \\
\hline
\end{tabular}

\section{Improve}

The last step - or the first in the new cycle - is to make changes based on the evaluation results, to improve the programmes that have been implemented, or to add on the next components. The evaluation may find that new needs have emerged that have not been addressed in the plan, so that a revision of the plan is required. Or possibly some techniques have not worked as well as anticipated, and need to be revised. On the other hand, some notable successes may have been achieved. It is important to recognize success, and to make sure that all the stakeholders are aware of it and continue to provide support. 


\section{References}

\footnotetext{
'Messing, Karen, and Piroska Östlin. "Gender Equality, Work and Health: A Review of the Evidence." Geneva: World Health Organization, 2006. WHO, 2006. Web. http://www.who.int/gender/documents/Genderworkhealth.pdf

ii "Return on Investment and Women's Health at the Workplace: A Study of HERproject in Egyptian Garment Factories." Rep. The Extending Service Delivery Project, 2011. Web. http://meridian-group.com/wp-content/uploads/2011/10/Egypt-HERproject-ROI-Study-FINAL-June-2011.pdf

iii Better Work. Impact Assessment. International Labour Organization, 2014. Web. http://betterwork.org/global/?page id=312

iv WHO. "Healthy Workplaces: A WHO Global Model for Action." Occupational Health. WHO, 2010. Web. http://www.who.int/occupational health/healthy workplaces/en/

${ }^{\vee}$ Necochea, Edgar, and Debora Bossemeyer. "Standards-Based Management and Recognition: A Field Guide." Jhpiego, 2005. Web. http://www.jhpiego.org/files/SBMR\%20FieldGuide.pdf

vi Sixtieth World Health Assembly. "Workers' Health: Global Plan of Action." WHO. 23 May 2007. Web. http://www.who.int/occupational health/WHO health assembly en web.pdf?ua=1

vii Committee on Economic, Social and Cultural Rights, General Comment No.14: The right to the highest attainable standard of health (Art. 12) (22 $2^{\text {nd }}$ Session, 2000)

viii Physicians for Human Rights. "AAAQ Framework." PHR Toolkits. 2010. Web.

http://phrtoolkits.org/toolkits/medical-professionalism/the-human-rights-basis-for-professionalism-in-healthcare/aaaq-framework/

${ }^{\text {ix }}$ Sjölund-Karlsson M, Reimer A, Folster JP, Walker M, Dahourou GA, Batra DG, et al. Drug resistance mechanisms in Vibrio cholerae $O 1$ outbreak strain, Haiti, 2010. Emerg Infect Dis. 2011 Nov. http://dx.doi.org/10.3201

x Better Work. "Research Brief: Improving Business Outcomes by Understanding What Matters to Workers." International Labour Organization and Internatinal Finance Corporation, 2013. Web. http://betterwork.org/global/wp-content/uploads/Research-Brief-What-Matters-to-Workers-LR.pdf

xi "WHO Healthy Workplace Framework and Model: Background Document and Supporting Literature and Practices," WHO, 2010. http://www.who.int/occupational health/healthy workplace framework.pdf

${ }^{\text {xii }}$ Reproduced, with the permission of the publisher, Burton, J. WHO Healthy Workplace Framework and Model: Background and Supporting Literature and Practice, Geneva World Health Organization. 2010.

http://www.who.int/occupational health/healthy workplace framework.pdf
} 
The Evidence Project

Population Council

4301 Connecticut Avenue, NW, Suite 280

Washington, DC 20008 USA

tel +12022379400

evidenceproject.popcouncil.org

\section{HERproject}

Business for Social Responsibility

85, Boulevard Haussmann

75008 Paris, France

tel +33 (0) 146479904

http://www.herproject.org/ 